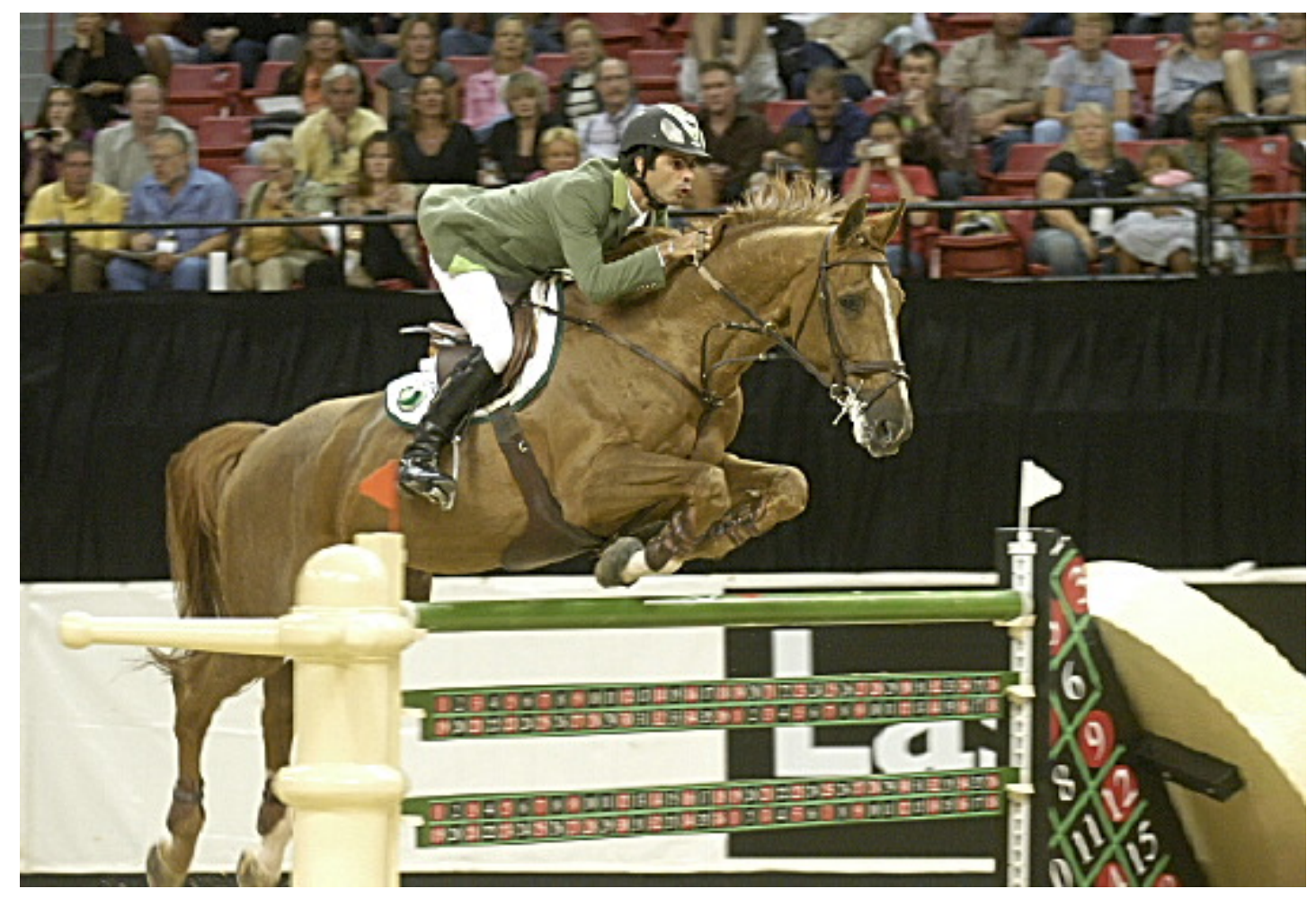

SÃO PAULO 


\section{CARLA VICCINO}

Ocorrência de hemorragia pulmonar induzida por esforço em cavalos de salto no Estado de São Paulo

Dissertação apresentada ao Programa de Pós-Graduação em Clínica Veterinária da Faculdade de Medicina Veterinária e Zootecnia da Universidade de São Paulo para a obtenção do título de Mestre em Medicina Veterinária

Departamento:

Clínica Médica

Área de Concentração:

Clínica Veterinária

Orientador:

Prof. Dr. Wilson Roberto Fernandes

SÃO PAULO 
Autorizo a reprodução parcial ou total desta obra, para fins acadêmicos, desde que citada a fonte.

DADOS INTERNACIONAIS DE CATALOGAÇÃO-NA-PUBLICAÇÃO

(Biblioteca Virginie Buff D’Ápice da Faculdade de Medicina Veterinária e Zootecnia da Universidade de São Paulo)

T.1878 Viccino, Carla

FMVZ Ocorrência de hemorragia pulmonar induzida por esforço em cavalos de salto no Estado de São Paulo / Carla Viccino. - São Paulo: C. Viccino, 2007.

$66 \mathrm{f}$ : : il.

Dissertação (mestrado) - Universidade de São Paulo. Faculdade de Medicina Veterinária e Zootecnia. Departamento de Clínica Médica, 2007.

Programa de Pós-Graduação: Clínica Veterinária.

Área de concentração: Clínica Veterinária.

Orientador: Prof. Dr. Wilson Roberto Fernandes.

1. Eqüinos. 2. Sistema respiratório. 3. HPIE. 4. Lavagem traqueobrônquica. 5. Hemossiderófagos. I. Título. 


\section{UNIVERSIDADE DE SÃO PAULO \\ Faculdade de Medicina Veterinária e Zootecnia \\ Cidade Universitária "Armando de Salles Oliveira"}

\section{Comissão de Bioética}

\section{CERTIFICADO}

Certificamos que o Projeto intitulado "Ocorrência de hemorragia pulmonar induzida por exercício em cavalos de salto", protocolo n648/2005, utilizando 100 cavalos, sob a responsabilidade do Prof. Dr. Wilson Roberto Fernandes, está de acordo com os princípios éticos de experimentação animal da Comissão de Bioética da Faculdade de Medicina Veterinária e Zootecnia da Universidade de São Paulo e foi aprovado "ad referendun".

(We certify that the Research "Occurrence of exercise induced pulmonary hemorrhage in jumping horses", protocol number 648/2005, utilizing 100 horses, under the responsibility of Prof. Dr. Wilson Roberto Fernandes, agree with Ethical Principles in Animal Research adopted by Bioethic Commission of the Faculty of Veterinary Medicine and Zootechny of University of São Paulo and was approved "ad referendun", meeting).

São Paulo, 29 de abril de 2005

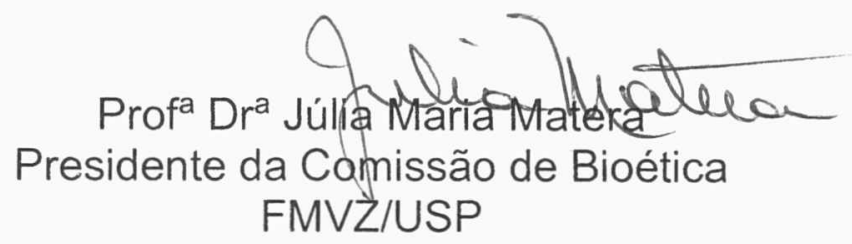




\section{FOLHA DE AVALIAÇÃO}

Nome: VICCINO, Carla

Título: Ocorrência de hemorragia pulmonar induzida por esforço em cavalos de salto no Estado de São Paulo

Dissertação apresentada ao Programa de PósGraduação em Clínica Veterinária da Faculdade de Medicina Veterinária e Zootecnia da Universidade de São Paulo para a obtenção do título de Mestre em Medicina Veterinária

Data:

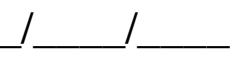

Banca Examinadora

Prof. Dr.

Instituição:

Assinatura: Julgamento:

Prof. Dr. Instituição:

Assinatura: Julgamento:

Prof. Dr. Instituição:

Assinatura: Julgamento: 
Aos meus pais, Antonio Carlos e Rosa Maria, pelo amor, direcionamento e ensinamentos.

Amo vocês! 


\section{AGRADECIMENTOS}

Ao Prof. Dr. Wilson Roberto Fernandes, pelos ensinamentos, apoio e paciência durante este trabalho.

A todos meus professores da graduação na UNISA e da pós-graduação na USP.

Aos funcionários do Hospital Veterinário e do Departamento de Clínica Médica da Faculdade de Medicina Veterinária e Zootecnia da Universidade de São Paulo, pelo auxílio neste trabalho.

Aos colegas Enio Mori, Lílian Emy dos Santos Michima e Carla Bargi Belli, pelo auxílio neste trabalho.

Ao amigo e gerente da Deltavet Jeff Talarico e a toda equipe Labyes/Deltavet, pelo apoio durante a realização deste trabalho.

À Sociedade Hípica Paulista, por permitir o uso das instalações do Departamento de Veterinária durante todo o experimento.

Ao Dr. Fábio Luiz Tuna Vieira, pela amizade e pelo apoio durante toda minha carreira e em especial neste projeto.

Aos enfermeiros da Sociedade Hípica Paulista, Aparecido, José Henrique, Daniel e Lalas, pelo auxílio na manipulação dos animais.

A todos os tratadores pelo auxílio na manipulação dos animais.

A Dra. Alma Y. A. Hoge e equipe do Laboratório da Sociedade Hípica Paulista, pelo auxílio na confecção e leitura das lâminas, na documentação fotográfica e na formatação do abstract deste trabalho.

Ao Prof. Walter Joaquim, pelo grande auxílio na formatação do abstract deste trabalho.

A todos os proprietários que gentilmente cederam seus animais para a realização deste experimento.

A todos os colegas veterinários, Dr. Fábio Luiz Tuna Vieira, Dra. Priscila Azevedo, Dra. Santina Moral, Dr. Rogério Pinheiro Passos, Dra. Sheila Largman, Dr. Marcelo Servos e Dra. Patrícia Brossi, que auxiliaram neste projeto intercedendo na liberação dos animais junto aos proprietários, sem a ajuda de vocês não poderia ter realizado este trabalho. 
A todos os veterinários colegas de trabalho, Adriana Garcia, Patrícia Fantini, Juliana Ramalho, Christiane Penna, Camila Sandoval, Juliane Pimentel, Hélio Itapema, Mauricio Alexandre, Claiton Pereira, Carla Omura, Marco Aurélio Gallo, Rogério Saito, Vanessa Sipas, Christian Carlstron, Flávio Moraes e Guilherme Kubo, pelos ótimos anos de convivência. 


\section{AGRADECIMENTOS EM ESPECIAL}

Durante toda minha vida tive a companhia de seres maravilhosos que me apoiaram sempre que eu precisei, agradeço a todos eles em especial.

A toda minha família, sempre orgulhosa com meu crescimento pessoal e profissional.

Aos meus pais, Rosa e Antonio Carlos, por tudo o que me deram.

Ao meu irmão André, pelo companheirismo e ajuda durante o trabalho.

A minha cunhada Rita, pelo carinho e amizade.

Ao meu padrinho Messias, por suas bênçãos e seus cuidados durante toda minha vida. A minha querida Tia Pina, pelo auxílio durante minha graduação, amor e apoio incondicional em minha vida. Sou eternamente grata a vocês.

A minha querida irmã Dani, por seu companheirismo e amizade eterna.

As minhas amigas de Salvador, Jú e Tati e suas famílias pelo apoio e amizade.

A minha amiga Mi, por todos os momentos juntas.

A minha amiga Dri e sua família, pela amizade e pelo grande apoio durante minha graduação.

Ao meu querido Prof. Dr. Antonio Fernandes Filho pelos ensinamentos e apoio durante minha graduação na UNISA.

Ao meu querido Prof. Dr. Celso Martins Pinto, pelos ensinamentos e grande auxílio durante minha graduação.

Aos meus amigos da UNISA, Dri, Dani, Paty, Khadine, Fafá, Camilinha, Jú Checheto, Fábio, Walter, Rodrigo, Pedrinho e Leandro, pelos momentos inesquecíveis.

Ao querido amigo e colega Dr. Gabriel Mott, pelos ensinamentos e auxílio na realização das endoscopias durante este trabalho. Muito Obrigada!

A minha cachorrinha Tuca, pelo companheirismo de 19 anos que me fizeram ter absoluta certeza que existe sim amor verdadeiro e incondicional.

A minha cachorrinha Nayla, que veio para alegrar minha vida e de minha família, perpetuando nosso amor pelos animais.

A todos os cavalos, que fizeram parte deste projeto e a todos aqueles com quem pude aprender e receber uma gratidão que não tem preço. 
"A mente que se abre a uma nova idéia jamais voltará ao seu tamanho original." 
VICCINO, C. Ocorrência de hemorragia pulmonar induzida por esforço em cavalos de salto no Estado de São Paulo. [Occurrence of effort induced pulmonary hemorrhage in jumper horse in the State of São Paulo]. 2007. 66f. Dissertação (Mestrado - em Medicina Veterinária). Faculdade de Medicina Veterinária e Zootecnia, Universidade de São Paulo, São Paulo, 2007.

A hemorragia pulmonar induzida por esforço (HPIE) ocorre com freqüência em cavalos atletas acarretando prejuízo econômico já que estes deverão ficar temporariamente afastados dos treinamentos e provas, além de receber tratamento adequado. O PuroSangue Inglês (PSI) utilizado em provas de corrida é o animal mais afetado devido ao grande esforço ao qual é submetido, porém animais de outras raças utilizados em outras modalidades de esportes hípicos também podem apresentar HPIE. O presente estudo teve como objetivo quantificar a ocorrência de casos de HPIE em animais utilizados em provas de salto, através do exame endoscópico e da análise citológica de amostras do lavado traqueobrônquico (LTB). Para a realização do presente experimento foram utilizados 50 cavalos adultos residentes nos clubes hípicos de São Paulo, que foram divididos em dois grupos, A e B, conforme as diferentes alturas dos obstáculos utilizados nas provas em que participaram. No grupo A foram inseridos os cavalos que saltam obstáculos de 1,00m a 1,20m de altura, e no grupo $B$, os cavalos que saltam obstáculos de 1,30m a 1,50m de altura. Foram realizados exames físicos destes animais, antes e depois da participação em uma prova. Após 1 hora do final da prova, os mesmos foram submetidos a um exame endoscópico em que eram observadas as possíveis alterações do trato respiratório anterior do animal sendo a principal delas a hemorragia pulmonar induzida por esforço. Foi realizada citologia do lavado traqueobônquico (LTB) por microscopia após citocentrifugação das amostras e posterior confecção das lâminas que foram então coradas por Rosenfeld. A principal observação durante a leitura das lâminas foi à presença de hemossiderófagos. No trabalho realizado são apresentados além da citologia do trato respiratório dados como os valores médios de freqüência cardíaca, freqüência respiratória e temperatura corpórea dos animais após a participação em uma prova. Estes dados foram relacionados às alturas dos obstáculos existentes em cada prova realizada pelos animais. Em relação à ocorrência de HPIE observamos que no grupo A $50 \%$ dos animais apresentaram HPIE e no grupo B a ocorrência foi de $66,67 \%$. Foram observados todos os graus de HPIE, porém somente no grupo B houve ocorrência de graus IV e V, demonstrando assim a correlação entre o nível de esforço realizado pelos cavalos de salto e o grau de HPIE apresentado por eles.

Palavras-chave: Eqüinos. Sistema respiratório. HPIE. Lavagem traqueobrônquica. Hemossiderófagos. 
VICCINO, C. Occurrence of effort induced pulmonary hemorrhage in jumper horse in the State of São Paulo. [Ocorrência de hemorragia pulmonar induzida por esforço em cavalos de salto no Estado de São Paulo]. 2007. 66f. Dissertação (Mestrado - em Medicina Veterinária). Faculdade de Medicina Veterinária e Zootecnia, Universidade de São Paulo, São Paulo, 2007.

Effort induced pulmonary hemorrhage (EIPH) frequently occurs in athlete horses causing economic losses not only due to temporary removal from training and competition, but also due to the cost of adequate treatment. Thoroughbreds used in racing are the most frequently affected breed due to the great effort to which they are submitted; however other breeds and crossbred sport horses can also have EIPH. The present study's objective is to quantify the occurrence of cases of EIPH in animals used in show jumping, through the endoscopic examination and cytological analysis of tracheobronchial lavage (TBL) samples. For the present experiment fifty adult horses, housed in maneges in the city of São Paulo, were used. Horses were divided into two groups, named A and B according to the different heights of the obstacles. Group A included horses that jump heights of 1.0 to $1.2 \mathrm{~m}$ and group $B$, obstacles of 1.3 to 1.5 m. Physical examinations of these animals were carried through, before and after participation in each test. One hour after the end of each series, the same ones had been submitted to an endoscopic examination where the possible alterations of previous the respiratory treatment of the animal were observed being main of them the induced pulmonary hemorrhage for effort. Cytology of tracheobronchial lavage (TBL) was performed in cytocentrifuge slides prepared on the same day, slides were stained using Rosenfeld Romanov and observed examined under light microscopy. The major focus during the observation of the slides was the presence of hemosiderophages and grading of EIPH intensity (I through $\mathrm{V}$ ) Besides the cytological evaluation of the respiratory tract, this study includes clinical data such as the average values of cardiac frequency, respiratory frequency and body temperature of the animals after the each competition. These data were correlated with the heights of the existing obstacles jumped by each athlete horse. In relation to the EIPH occurrence we observed that in the group A 50\% of the animals presented EIPH and in group B the occurrence was of $66,67 \%$. All grades of EIPH were observed when both groups were considered, however only animals in group B showed intense hemorrhage levels (IV or $\mathrm{V}$ ) thus demonstrating and the correlation between the levels of effort the intensity of EIPH in jumpers.

Key words: Equines. Respiratory system. EIPH. Tracheobronchial lavage. Hemosiderophages 


\section{LISTA DE FIGURAS}

Figura 1 - Foto representativa do grau I de hemorragia pulmonar induzida por exercício.

Figura 2 - Foto representativa do grau II de hemorragia pulmonar induzida por exercício.

Figura 3 - Foto representativa do grau III de hemorragia pulmonar induzida por exercício......

Figura 4 - Foto representativa do grau IV de hemorragia pulmonar induzida por exercício.

Figura 5 - Foto ilustrativa da amostra de lavado traqueobrônquico avermelhado, turvo com partículas pequenas (HPIE G III)

Figura 6 - Foto ilustrativa da amostra de lavado traqueobrônquico vermelho, turvo sem partículas (HPIE G IV).

Figura 7 - Fotomicrografaia de células do lavado traqueobrônquico de cavalo. Em destaque: 1. Macrófagos; 2. Eosinófilo; 3. Linfócito; 4. Neutrófilo. Coloração de Rosenfeld. Microscopia óptica de imersão, aumento 800x ....54

Figura 8 - Fotomicrografaia de células do lavado traqueobrônquico de cavalo. Em destaque: 1. Macrófago binucleado; 2. Macrófago. Coloração de Rosenfeld. Microscopia óptica de imersão, aumento 800x.

Figura 9 - Fotomicrografaia de células do lavado traqueobrônquico de cavalo. Em destaque: 1. Hemossiderófago. Coloração de Rosenfeld. Microscopia óptica de imersão, aumento 800x....

Figura 10 - Fotomicrografaia de células do lavado traqueobrônquico de cavalo. Em destaque: 1. Hemossiderófago; 2. Linfócito. Coloração de Rosenfeld. Microscopia óptica de imersão, aumento 800x.

Figura 11 - Fotomicrografaia de células do lavado traqueobrônquico de cavalo. Em destaque: 1. Célula epitelial cilíndrica ciliada. Coloração de Rosenfeld. Microscopia óptica de imersão, aumento 800x. 


\section{LISTA DE TABELAS}

Tabela 1 - Relação dos cavalos utilizados do grupo A …................................................. 28

Tabela 2 - Relação dos cavalos utilizados do grupo B ............................................. 29

Tabela 3 - Parâmetros clínicos dos animais do grupo A aferidos em repouso e após o esforço

Tabela 4 - Parâmetros clínicos dos animais do grupo B aferidos em repouso e após o esforço.

Tabela 5 - Resultado do exame semiológico do trato respiratório dos animais do grupo A observados antes e após o esforço.

Tabela 6 - Resultado do exame semiológico do trato respiratório dos animais do grupo B observados antes e após o esforço.

Tabela 7 - Relação da altura dos obstáculos das provas realizadas pelos animais dos grupos A e B e o grau de hemorragia pulmonar induzida por esforço apresentada durante este estudo

Tabela 8 - Ocorrência de casos de hemorragia pulmonar induzida por esforço em cavalos de salto do grupo A.

Tabela 9 - Ocorrência de casos de hemorragia pulmonar induzida por esforço em cavalos de salto do grupo $B$.....

Tabela 10 - Volume recuperado de amostras do lavado traqueobrônquico dos animais dos grupos A e B

Tabela 11 - Características macroscópicas das amostras do lavado traqueobrônquico dos animais do grupo $\mathrm{A}$

Tabela 12 - Características macroscópicas das amostras do lavado traqueobrônquico dos animais do grupo B

Tabela 13 - Média e desvio padrão dos tipos celulares observados nas amostras do lavado traqueobrônquico dos animais do grupo A relacionados ao grau de hemorragia pulmonar induzida por esforço

Tabela 14 - Média e desvio padrão dos tipos celulares observados nas amostras do lavado traqueobrônquico dos animais do grupo B relacionados ao grau de hemorragia pulmonar induzida por esforço 


\section{LISTA DE QUADRO}

Quadro 1 - Classificação das amostras do lavado traqueobrônquico colhido dos animais. 


\section{LISTA DE ABREVIATURAS E DE SÍMBOLOS}

bpm: batimentos por minuto

${ }^{\circ} \mathrm{C}$ : graus centígrados

Cel. Ep. Cilínd. Cil.: célula epitelial cilíndrica ciliada

FC: freqüência cardíaca

Fig.: figura

FR.: freqüência respiratória

G: grau

HPIE: hemorragia pulmonar induzida por esforço

Kg: quilos

LBA: lavado broncoalveolar

LTB: lavado traqueobrônquico

m: metros

min.: minutos

ml: mililitros

mm: milímetros

mmHg: milímetros de mercúrio

mpm: movimentos por minuto

rpm: rotações por minuto

$\mathrm{T}$ : temperatura

\pm : mais ou menos

$\mu \mathrm{L}$ : microlitro 


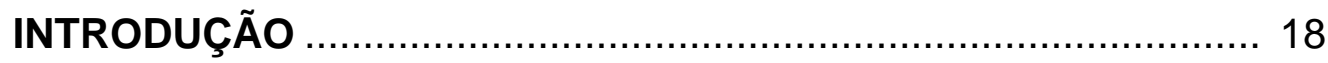

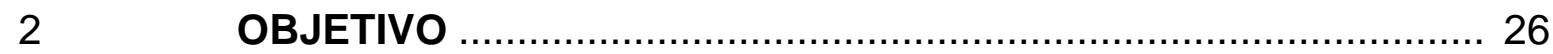

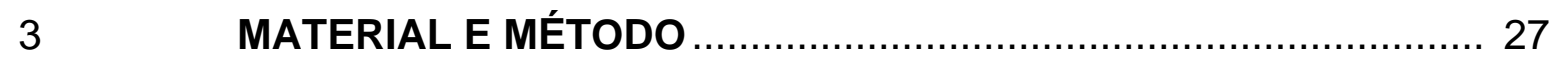

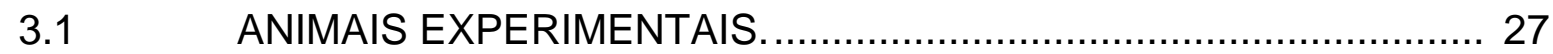

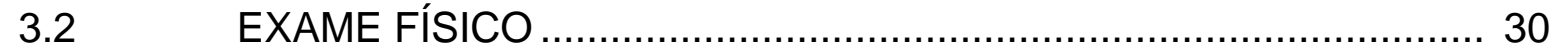

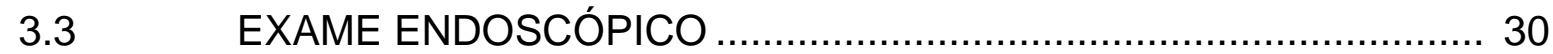

3.4 ANÁLISE DO LAVADO TRAQUEOBRÔNQUICO (LTB) .................. 32

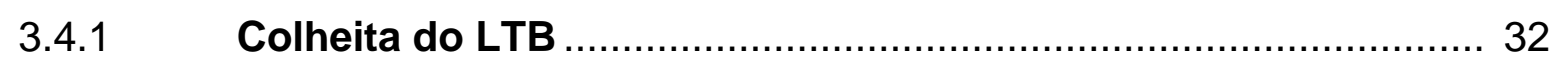

3.4.2 Características macroscópicas do LTB...................................... 33

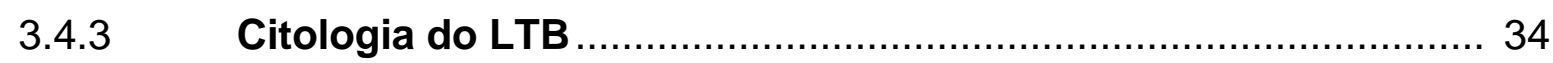

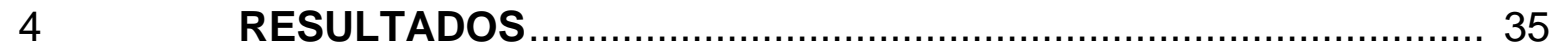

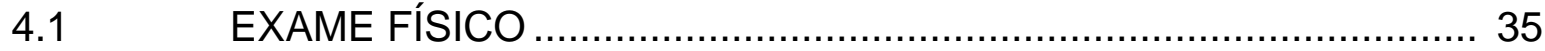

4.1.1 Parâmetros obtidos antes do exercício ......................................... 35

4.1.2 Parâmetros obtidos após o exercício ………………………....... 36

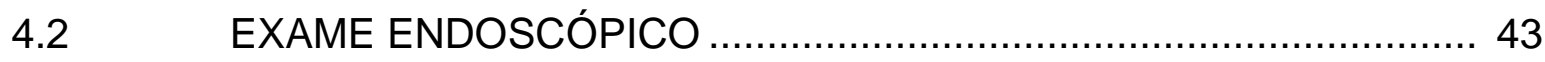

4.3 ANÁLISE DO LAVADO TRAQUEOBRÔNQUICO (LTB) .................. 46

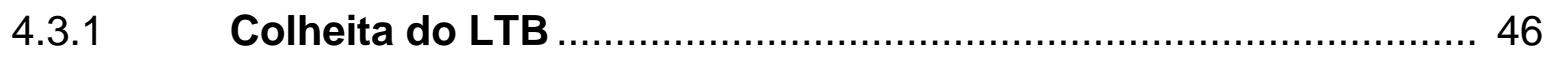

4.3.2 Características macroscópicas do LTB.................................. 48

4.3.3 Citologia do LTB ................................................................. 51

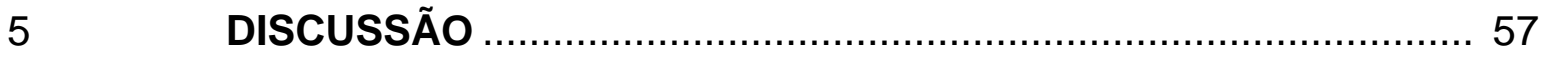

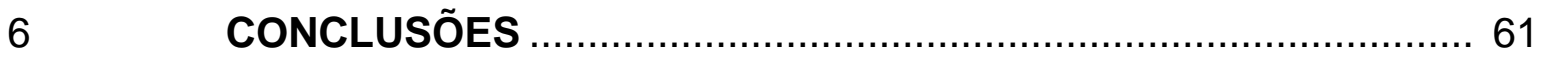

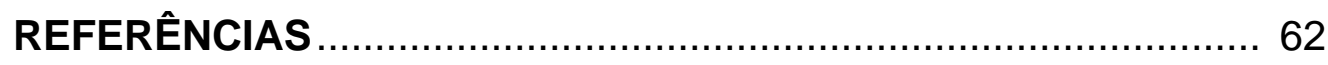




\section{INTRODUÇÃO}

A hemorragia pulmonar induzida por esforço (HPIE) é uma conseqüência fisiológica de exercícios extenuantes (PASCOE et al., 1995). O fenômeno da HPIE começa com um processo focal, seguido de inflamação peribronquial principalmente na região pulmonar dorsocaudal que resulta em uma neovascularização arterial bronquial (DONALDSON, 1991). Este processo pode ser explicado pelo fato de que a região dorsocaudal dos pulmões tem grande capacidade de redistribuição do fluxo sangüíneo por ter propriedades elásticas diferentes do restante do parênquima pulmonar, além de grande densidade de capilares (DONALDSON, 1991). Esta hipótese pode ser reforçada levando-se em consideração a descrição da circulação do sangue pelos pulmões feita por Sweeney e Beech (1991). Estes autores descrevem que existem duas vias de acesso do sangue para os pulmões do eqüino, a circulação pulmonar e a circulação bronquial, sendo que a circulação pulmonar que apresenta grande volume e baixa pressão está diretamente envolvida na troca gasosa e na distribuição de oxigênio aos músculos e que é nesta região que ocorre um aumento da pressão e de fluxo sangüíneo durante o exercício.

Além disso, durante a realização de um determinado esforço ocorrem vários eventos fisiológicos no organismo do animal tais como: o aumento da freqüência cardíaca; aumento do débito cardíaco produzido pelo aumento da freqüência cardíaca; aumento das atividades simpáticas, que estimulam o miocárdio diretamente reduzindo o volume sangüíneo no ventrículo no final do movimento sistólico; aumento do fluxo sangüíneo para os pulmões porque mais capilares e alvéolos pulmonares se abrem; elevação na freqüência respiratória causando aumento na pressão intratorácica negativa e desta forma ajudando o retorno venoso para o coração. As veias coronárias do miocárdio aumentam de tamanho, melhorando a oxigenação do órgão vital, uma redistribuição de sangue para a periferia e particularmente para a musculatura esquelética com vasoconstrição de veias na área esplênica, aumento do fluxo sangüíneo para a pele para melhorar a perda de calor, aumento da movimentação muscular para melhorar o fluxo sangüíneo que ajuda o retorno de sangue para o coração mais rapidamente (JONES, 1989). 
A pressão sangüínea do animal durante o exercício sofre evidente alteração, tanto a pressão pulmonar quanto as pressões arterial e venosa. As pressões nos pulmões bem como em ambos os lados da circulação sistêmica do eqüino são marcantemente elevadas durante o exercício em piscina, embora somente a pressão arterial média da carótida tenha aumento relacionado com esforço máximo neste exercício. Marcado aumento de pressão atrial média, ventricular direita, e arterial pulmonar é observado em exercícios feitos em piscina, porém estão pouco relacionados com esforço máximo (JONES, 1989).

Em um treinamento de corrida realizado com cinco estágios contínuos foi relatado que as pressões sangüíneas em ambos os lados, direito e esquerdo da circulação, foram significantemente elevadas. A pressão sistólica ventricular esquerda passou de $140 \pm 5 \mathrm{mmHg}$ em repouso para $217 \pm 15 \mathrm{mmHg}$ no $5^{\circ}$ estágio (esforço máximo), sendo que a pressão diastólica final permaneceu com os mesmos valores. Um aumento em ambas as pressões, diastólica e sistólica na circulação arterial, foi responsável por um aumento de $30 \mathrm{mmHg}$ na pressão aórtica média neste nível do exercício. O aumento da pressão aórtica sistólica foi maior do que o observado na pressão aórtica diastólica. A pressão atrial média direita, um indicador das pressões no lado venoso da circulação, aumentou de $7 \pm 1 \mathrm{mmHg}$ em repouso para $16 \pm 2$ mmHG no $5^{\circ}$ estágio (esforço máximo) (JONES, 1989).

Uma série de alterações fisiológicas também é evidenciada nos pulmões, a mais característica é a hipertensão pulmonar, gerada pelo aumento da pressão transmural dos capilares e vascular dos pulmões, aumento do débito cardíaco em dez vezes para suprir o grande aumento do consumo de oxigênio, aumento da viscosidade em duas vezes causada pelo aumento do volume das células sangüíneas de 40 a 60\% que sofrem alterações morfológicas e tornam-se mais frágeis osmoticamente e aumento da pressão atrial esquerda em dez vezes (PASCOE et al., 1995).

A habilidade vascular pulmonar para responder ao aumento de carga e volume é limitada pelo espaço vascular disponível e por forças mecânicas na bomba respiratória. A resistência das vias aéreas pode limitar a ventilação alveolar causando hipóxia alveolar. Limitações de difusão e/ou ligações extra pulmonares contribuem para a hipoxemia arterial. A hipóxia alveolar e hipoxemia arterial induzem dilatação da artéria bronquial e aumento do fluxo sangüíneo, aumentando a carga na vascularidade pulmonar via anastomoses broncopulmonares (PASCOE et al., 1995). 
O aumento da viscosidade sangüínea secundária a mobilização eritrocitária devido à contração esplênica, ocorre para garantir o aumento da demanda de oxigênio, contribui para a resistência do fluxo sangüíneo e pode indiretamente aumentar a pressão intravascular pulmonar. Estes fatores são suficientes para causar rompimentos de capilares pulmonares saudáveis (PASCOE, 1991).

Todos os eventos descritos acima ocorrem no organismo do animal durante a realização de exercícios e podem estar diretamente relacionados com o fenômeno da HPIE. Existem inúmeras hipóteses sobre a patogenia da HPIE, uma delas foi determinada por Robinson (1979), que se baseou em vários fatores. Este autor descreveu que durante o exercício ocorre o aumento da pressão sangüínea bronquial e pulmonar que juntamente com a vasoconstrição pulmonar que leva a hipóxia, causam o aumento da pressão transmural dos capilares. Um aumento da pressão transpulmonar leva a um aumento da pressão das forças de fricção do interstício do septo pulmonar; fator este que é também influenciado pela hipóxia causada pela vasoconstrição pulmonar. As forças no septo pulmonar juntamente com o aumento da pressão transmural dos capilares levam a uma interrupção local do tecido ocorrendo assim uma hemorragia focal e esta leva a inflamação local.

Outra hipótese foi sugerida por O' Callaghan (1987), que relatou alguns eventos fisiológicos que ocorrem durante o exercício, como, hipóxia alveolar local por vasoconstrição pulmonar e vasodilatação bronquial, que juntamente com a hipertensão sistêmica e pulmonar levam a hemorragia focal. A hipóxia alveolar provoca neovascularização nos capilares dos brônquios, que contribui para a ocorrência da hemorragia.

Existem alguns fatores predisponentes em relação à HPIE, tais como, estresse mecânico (aumento da pressão nos vasos), tamanho dos pulmões e tórax, efeitos gravitacionais e pequenas doenças pulmonares (bronquiolites) (CLARKE, 1985).

De acordo com alguns estudos feitos em cavalos de corrida que apresentaram HPIE, este fenômeno quando de pequena monta, não prejudica o desempenho do animal porém pode causar inflamações de vias aéreas e eventualmente doenças nas pequenas vias aéreas.

Clarke (1985) propôs que a HPIE é primariamente causada por estresse mecânico na região dorsocaudal do pulmão. Nesse trabalho o autor descreveu a patogenia detalhando achados de necropsia e estudos histopatológicos dos pulmões de cavalos que sofreram HPIE, além das características radiológicas deste 
fenômeno bem como sobre sua etiologia. Em relação à etiologia Clarke citou alguns fatores para explicar o fenômeno da HPIE, sendo a doença pulmonar crônica um deles, porém outros autores como Spens et al. (1982) e Burrel (1985), não observaram associação entre HPIE e doenças pulmonares.

Raphel (1982), não encontrou correlação entre HPIE e hiperplasia linfóide da faringe ou HPIE com hemiplegia laringeana, baseado num estudo com 479 cavalos. Rooney (1970), sugeriu que a asfixia resultante de momentos ofegantes ou de obstruções parciais de vias aéreas ocasionadas, por exemplo, pela hemiplegia laringeana, distendem espaços aéreos e comprometem o fluxo sangüíneo através da obstrução de veias pulmonares.

Robinson (1979), rebateu essas afirmações por entender que: é improvável que um cavalo fique ofegante ao ponto de asfixiar-se e que a hemiplegia normalmente causa obstrução durante a inspiração, portanto é improvável que cause hiperinflação nos pulmões. Além disso, a inflação dos pulmões causa dilatação de vasos antes de causar obstrução e a superinflação dos pulmões, durante a expiração, pode causar oclusão dos capilares pela pressão transmural; levando o fluxo sangüíneo para a porção superdistendida do pulmão.

Derkensen e Robinson (1980) acreditam que hemorragias pulmonares resultam de grandes forças de distensão em algumas áreas dos pulmões que não ventilavam sincronizadamente com o resto do órgão por causa de obstruções inaparentes de vias aéreas. Eles sugeriram que, uma ventilação colateral pobre nos pulmões de cavalos atletas causa extrema variação da pressão alveolar na região sem sincronismo, produzindo ruptura parenquimal ou de capilares. Esta teoria foi baseada na propriedade de interdependência de lóbulos pulmonares.

Outro fator que Clarke (1985) destacou foi a obstrução de vias superiores e asfixia, que foi considerada possível precursora da HPIE pelo fato de provocar um aumento de pressão negativa nos alvéolos pulmonares por causa da diminuição da resistência ou super inflação dos alvéolos (ROONEY, 1970; ROBINSON, 1979).

A hipertensão pulmonar também foi citada como causa de HPIE em estudo de John et al. (1984) que relatou 10 cavalos com epistaxe e hipertensão pulmonar. Johnson et al. (1973), encontrou um aumento na ocorrência de hipertensão arterial num grupo de cavalos que sofreram epistaxe quando comparados a outro grupo que não apresentou tal sintoma. Não foram feitos exames antes da epistaxe, portanto não se sabe se a hipertensão é primária, secundária ou não tem relação com a 
HPIE. Estas observações foram baseadas na presença ou ausência de sangue nas narinas e sem evidências endoscópicas.

Robinson (1979), afirmou que a pressão dos capilares pode aumentar suficientemente para romper veias pulmonares antes da hemorragia. Entretanto, diminui gradualmente e o cavalo começa a ficar dispnéico antes deste fenômeno.

Similarmente obstruções de vias aéreas superiores não mostram contribuir para uma queda de pressão intralveolar ao ponto de ocorrer hemorragia, sem primeiro promover movimento fluídico generalizado dentro do interstício e espaços alveolares (ROBINSON, 1979). O tromboembolismo, a infestação por parasitas e a peneumonia focal foram outros agentes causadores de obstruções pulmonares citados por Clarke (1985).

Gpulden e O' Callaghan (1982), sugeriram que como o local da maioria das lesões nos pulmões dos animais que sofreram epistaxe é a porção caudal do lobo diafragmático, há a possibilidade das hemorragias serem previamente causadas por parasitas, trombos e bactérias invasoras que também causam lesão preferencialmente nesta região. Porém os achados histológicos de Mason et al. (1983), não mostraram evidências de lesões causadas por parasitas ou tromboembolismo com ou sem infarto.

Pascoe et al. (1983), sugeriram que as lesões que apresentaram resolução rapidamente após ter ocorrido hemorragia, podem ter ocorrido em vias aéreas distais por edemas pulmonares hemorrágicos ou tromboembolismo sem infarto. Através de achados histológicos, exames clínicos, lavados traqueais e achados radiológicos realizados por Johnson et al. (1973) e Pascoe et al. (1983), e foi sugerido que infecções secundárias podem ocorrer no local da hemorragia.

Uma significante trombocitopenia e diminuição do tempo de coagulação foram observadas por Johnson et al. (1973), em cavalos que tiveram quadros de epistaxe comparados com cavalos que não sofreram epistaxe.

Hall e Jeffcott (1979), mostraram que as vísceras abdominais têm efeito no estresse dos pulmões. A massa absoluta do conteúdo abdominal do cavalo causa resistência ao movimento diafragmático, sendo esta maior na porção ventral do que na dorsal.

Clarke (1985), comentou sobre um fator considerado muito importante por muitos estudiosos, o estresse mecânico. Suas conclusões finais sugeriram que, condições clínicas ou assintomáticas pré-existentes podem tornar os cavalos mais 
suscetíveis à HPIE por causa da exacerbação do estresse mecânico que ocorre nesses animais. Entretanto, as condições pré-existentes não precisam ser necessariamente as causas iniciais da HPIE. As seguintes afirmações citadas pelo autor indicam que a HPIE aparece em resposta a um estresse mecânico antes que doenças respiratórias: o início de ocorrências de hemorragias em animais PuroSangue em treinamento, coincide com o começo do trabalho rápido em cavalos de dois anos de idade que pela pouca idade têm menos chances de adquirirem uma doença respiratória; HPIE sempre ocorre no mesmo local dentro do pulmão; HPIE tem distribuição mundial dependente de fatores climáticos, local de estabulagem, manejo e etc; HPIE ocorre freqüentemente e certo tipo de esforço é necessário para induzir a HPIE.

Em 1998, Smith e Weiss abordaram as alterações hematológicas associadas com cavalos de corrida e as implicações pela HPIE. Neste trabalho foram colocadas três hipóteses que serão descritas a seguir. A primeira baseada em trabalho de O'Callaghan et al. (1987): uma inflamação crônica de vias aéreas inferiores resulta em uma neovascularização brônquica que pode causar rompimentos estruturais de vasos e desregularão do fluxo sangüíneo. A segunda baseada em trabalho de West et al. (1993) e Manohar (1994): que estresses induzem rompimentos de capilares pulmonares, resultando em um aumento do débito cardíaco, e em alteração de propriedades do sangue (MCCLAY et al., 1982; WEISS et al., 1996). A terceira hipótese baseada nas citações de Johnstone et al. (1991) e Mahony et al. (1992): que existe a predisposição dos cavalos à hemorragia.

Um Workshop realizado em (Association of Racing Commissioners International Drug Testing and Quality Assurance Program) conclui que a HPIE pode ocorrer por uma combinação de estresse durante a corrida com aumento da pressão sangüínea e da viscosidade do sangue e também por uma doença local nas pequenas vias aéreas (SMITH, 1992).

Manohar (1993), descreveu dados relativos a alterações de pressão e afirmou que estas alterações levam à um aumento do fluxo cardíaco e da viscosidade sangüínea. O fluxo cardíaco atinge uma média de $750 \mathrm{ml} / \mathrm{min} / \mathrm{Kg}$ e a freqüência cardíaca máxima chega a 240bpm nos animais Puro-Sangue de corrida (FEDDE et al., 1993; MANOHAR, 1993).

Um grande aumento na viscosidade sangüínea também ocorre durante a corrida e o treinamento. Este aumento é primário, mas não exclusivo, devido ao 
exercício associado com aumento no volume celular (MCCLAY et al., 1992; GEOR et al., 1994).

Resultados de estudos in vitro e in vivo indicam que o volume celular contribui substancialmente para forças de fricção na microvasculatura (GEOR et al., 1994; MCCLAY et al., 1994; WEISS et al., 1994, 1996).

Em um trabalho realizado por Weiss e Smith (1998), foram descritas detalhadamente alterações hematológicas que ocorrem nos animais durante a participação dos mesmos em uma corrida como, as forças que agem nas paredes dos vasos (estresse circunferencial e pressão capilar), os efeitos destas alterações e os métodos para a avaliação das propriedades sangüíneas (viscosidade sangüínea, deformidade dos eritrócitos, volume eritrocitário e concentração de hemoglobina, densidade eritrocitária, taxa de sedimentação dos eritrócitos e viscosidade plasmática). Os autores tiveram como objetivo neste estudo padronizar e explorar técnicas que possam avaliar as condições hematológicas dos animais já que consideram que alterações destas condições podem levar a ocorrência de HPIE.

Meyer et al. (1998), realizaram um estudo em que foram avaliadas algumas alterações fisiológicas ocorridas nos animais após realização de exercícios. O principal objetivo dos autores foi quantificar casos de HPIE através da análise do lavado broncoalveolar (LBA).

O estudo foi realizado com seis animais divididos em dois grupos, quatro cavalos normais divididos no grupo I e 2 cavalos com hemiplegia laringeana (graus III e IV) no grupo II. Durante este estudo nenhum caso de epistaxe foi observado e nenhuma evidência de HPIE foi observada pelo exame endoscópico. Porém através da análise citológica das amostras obtidas do LBA, foi observada a presença de hemossiderófagos, a porcentagem destas células foi aumentando após alguns dias do exercício realizado e seu valor máximo foi observado na segunda semana e a partir desta começou a diminuir gradativamente até a quinta semana.

$\mathrm{Na}$ discussão dos resultados os autores relataram que em animais que não apresentam sinais de epistaxe nem evidências de HPIE através do exame endoscópico, a realização do LBA pode auxiliar no diagnóstico de casos de HPIE inaparentes, através da contagem do número de hemossiderófagos nas amostras obtidas por esta técnica.

Outro estudo realizado em 1991 por Burckley e Forgaty também relacionaram resultados encontrados através da avaliação de fluídos de lavados broncoalveolares 
(LBA) nos cavalos com intolerância ao exercício. Foram utilizados 76 animais divididos em dois grupos, 11 animais Puro-Sangue entre 2 e 6 anos no grupo A e 65 animais Puro-Sangue entre 2 e 9 anos no grupo B que tinham mostrado severos sinais de intolerância ao exercício quando submetidos a grandes esforços. Todos os animais do grupo A foram submetidos ao exame endoscópico e no grupo B foram examinados 47 animais. O LBA foi realizado em todos os animais deste estudo através de técnica descrita por Forgaty (1990). A principal observação sobre as amostras do LBA foi a presença de hemossiderófagos e estes foram expressos em porcentagem sobre o número de macrófagos observados na contagem diferencial. A detecção de HPIE foi baseada na presença destas células com ou sem células vermelhas intra ou extra celulares (GREET; WHITWELL, 1984). A HPIE foi graduada na relação direta com o aumento da porcentagem de hemossiderófagos presentes (FORGATY, 1990).

Em relação aos resultados os autores observaram que hemossiderófagos estavam presentes em todos os cavalos dos grupos A e B. A porcentagem de hemossiderófagos dos cavalos do grupo B foi significantemente maior do que dos cavalos do grupo A. No grupo A, a porcentagem foi de $21 \pm 19 \%$ (média e desvio padrão) e no grupo $B$, foi de $44 \pm 28 \%$ (média e desvio padrão). No grupo B 43\% (28/65) dos cavalos tinham mais que $50 \%$ de hemossiderófagos, já no grupo $A$ nenhum cavalo tinha 50\% de hemossiderófagos e 55\% (6/11) destes animais tinham menos que $20 \%$ destas células. A detecção de sangue nas narinas ou na traquéia dos cavalos dos grupos A e B, foi associada com o aumento do percentual de hemossiderófagos, de 12 para 87\% (média e desvio padrão de $39 \pm 24 \%$ ).

Através de todos estes estudos podemos notar que a análise de fluídos do sistema respiratório do eqüino é muito importante para que possamos afirmar a ocorrência da HPIE nos cavalos. Por isto, no presente estudo avaliaremos amostras de aspirados traqueais, associado ao exame endoscópico, realizado nos cavalos utilizados para a prática do hipismo clássico. 


\section{OBJETIVO}

Avaliar a ocorrência de casos de hemorragia pulmonar induzida por esforço (HPIE) em eqüinos utilizados em provas de salto, por meio de exame endoscópico e análise citológica de amostras de lavado traqueobrônquico (LTB) colhidas durante o mesmo e determinar a possível influência do nível de esforço sobre esta ocorrência. Além da avaliação de dados como freqüência cardíaca (FC), freqüência respiratória (FR) e temperatura corporal, na tentativa de correlacionar casos de HPIE com mudanças de condições circulatórias. 


\section{MATERIAL E MÉTODO}

Segue abaixo a metodologia utilizada no presente estudo.

\subsection{ANIMAIS EXPERIMENTAIS}

Foram utilizados 50 cavalos (Equus cabalus - LINNAEUS, 1758) alojados em clubes hípicos na cidade de São Paulo que participam regularmente de provas de salto, dentre eles 42 eram da raça Brasileiro de Hipismo (BH). Estes animais foram distribuídos em dois grupos. Grupo A (Tabela 1), constituído por animais que saltam obstáculos de $1.00 \mathrm{~m}$ a $1.20 \mathrm{~m}$ de altura e grupo B (Tabela 2), constituído por animais que saltam obstáculos de $1.30 \mathrm{~m}$ a $1.50 \mathrm{~m}$ de altura.

Estes animais foram mantidos em Clube Hípicos na cidade de São Paulo, em baias individuais de cerca de $16 \mathrm{~m}^{2}$, em cama de maravalha e alimentados com ração comercial, feno e capim "in natura", além de água "ad libitum", sendo submetidos a treinamento físico semelhante. 
Tabela 1 - Relação dos cavalos utilizados no GRUPO A

\begin{tabular}{|c|c|c|c|c|}
\hline$\overline{\text { ANIMAL }}$ & IDADE (anos) & PESO (Kg) & SEXO & $\begin{array}{c}\text { ALTURA DOS } \\
\text { OBSTÁCULOS (M) }\end{array}$ \\
\hline 1 & 11 & 437 & $F$ & 1.20 \\
\hline 2 & 9 & 398 & $\mathrm{~F}$ & 1.10 \\
\hline 3 & 12 & 425 & M & 1.10 \\
\hline 4 & 10 & 372 & M & 1.00 \\
\hline 5 & 9 & 392 & M & 1.10 \\
\hline 6 & 13 & 510 & M & 1.20 \\
\hline 7 & 9 & 374 & M & 1.10 \\
\hline 8 & 12 & 501 & M & 1.10 \\
\hline 9 & 14 & 387 & M & 1.00 \\
\hline 10 & 11 & 433 & M & 1.20 \\
\hline 11 & 10 & 388 & M & 1.10 \\
\hline 12 & 7 & 421 & M & 1.00 \\
\hline 13 & 9 & 547 & $\mathrm{~F}$ & 1.20 \\
\hline 14 & 11 & 529 & M & 1.20 \\
\hline 15 & 14 & 542 & $\mathrm{~F}$ & 1.20 \\
\hline 16 & 12 & 513 & M & 1.20 \\
\hline 17 & 11 & 472 & M & 1.10 \\
\hline 18 & 11 & 399 & $\mathrm{~F}$ & 1.00 \\
\hline 19 & 10 & 516 & M & 1.20 \\
\hline 20 & 8 & 539 & $\mathrm{~F}$ & 1.20 \\
\hline 21 & 9 & 374 & M & 1.00 \\
\hline 22 & 12 & 412 & M & 1.20 \\
\hline 23 & 12 & 563 & M & 1.20 \\
\hline 24 & 11 & 475 & $\mathrm{~F}$ & 1.00 \\
\hline 25 & 13 & 527 & $\mathrm{~F}$ & 1.20 \\
\hline 26 & 9 & 544 & $\mathrm{~F}$ & 1.20 \\
\hline$\ldots$ & $10,73 \pm 1,80^{*}$ & $461,15 \pm 66,17^{*}$ & $17 \mathrm{M}$ e $9 \mathrm{~F}^{*}$ & 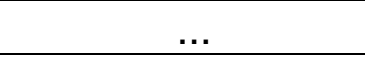 \\
\hline
\end{tabular}

*Média e desvio padrão

*M: Macho

*F: Fêmea 
Tabela 2 - Relação dos cavalos utilizados no GRUPO B

\begin{tabular}{|c|c|c|c|c|}
\hline$\overline{\text { ANIMAL }}$ & IDADE (anos) & PESO (Kg) & SEXO & $\begin{array}{c}\text { ALTURA DOS } \\
\text { OBSTÁCULOS (M) }\end{array}$ \\
\hline 27 & 12 & 501 & $M$ & 1.30 \\
\hline 28 & 6 & 512 & M & 1.30 \\
\hline 29 & 12 & 537 & M & 1.30 \\
\hline 30 & 13 & 520 & M & 1.30 \\
\hline 31 & 9 & 536 & M & 1.40 \\
\hline 32 & 11 & 522 & M & 1.50 \\
\hline 33 & 12 & 541 & M & 1.50 \\
\hline 34 & 10 & 479 & $\mathrm{~F}$ & 1.40 \\
\hline 35 & 6 & 567 & M & 1.30 \\
\hline 36 & 7 & 546 & $\mathrm{~F}$ & 1.40 \\
\hline 37 & 9 & 539 & M & 1.50 \\
\hline 38 & 7 & 509 & M & 1.40 \\
\hline 39 & 11 & 516 & $\mathrm{~F}$ & 1.30 \\
\hline 40 & 10 & 577 & M & 1.30 \\
\hline 41 & 10 & 549 & M & 1.30 \\
\hline 42 & 11 & 544 & M & 1.30 \\
\hline 43 & 7 & 532 & $\mathrm{~F}$ & 1.40 \\
\hline 44 & 13 & 527 & M & 1.40 \\
\hline 45 & 12 & 496 & M & 1.50 \\
\hline 46 & 12 & 542 & $\mathrm{~F}$ & 1.50 \\
\hline 47 & 11 & 537 & M & 1.30 \\
\hline 48 & 6 & 518 & M & 1.30 \\
\hline 49 & 11 & 549 & $\mathrm{~F}$ & 1.30 \\
\hline 50 & 7 & 532 & M & 1.40 \\
\hline$\ldots$ & $9,80 \pm 2,36^{*}$ & $530,33 \pm 22,00^{*}$ & $18 \mathrm{M}$ e $6 \mathrm{~F}^{*}$ & $\ldots$ \\
\hline
\end{tabular}

*Média e desvio padrão

*M: Macho

*F: Fêmea 


\subsection{EXAME FÍSICO}

Todos os animais do experimento foram submetidos ao exame físico antes da participação em suas respectivas provas e logo em seguida do término das mesmas.

No exame físico foram aferidas as freqüências, cardíaca e respiratória por meio de auscultação por fonendoscópio, e a temperatura corpórea dos animais (STÖBER, 1993; SPEIRS, 1997).

O sistema respiratório foi avaliado com a utilização de meios semiológicos para a detecção de possíveis sinais clínicos compatíveis com doença respiratória. $\mathrm{Na}$ inspeção direta observou-se as narinas dos animais analisando as mucosas nasais quanto à sua coloração, a presença de secreção nasal unilateral ou bilateral avaliando seu aspecto físico (seroso, mucoso, mucopurulento ou sanguinolento).

$\mathrm{Na}$ auscultação, através de fonendoscópio, de alguns campos pulmonares na região do tórax e a auscultação por meio de fonendoscópio da região da traquéia foi realizada com o intuito de pesquisar a presença de ruídos respiratórios (STÖBER, 1993; SPEIRS, 1997).

\subsection{EXAME ENDOSCÓPICO}

Para a visualização interna do trato respiratório anterior, utilizou-se a técnica de endoscopia (colonoscópio flexível da marca Pentax com fibra óptica de 1,70m de comprimento). Este exame foi realizado com os animais em estação contidos por um enfermeiro através de um "cachimbo". Os eqüinos não foram sedados para evitar qualquer alteração na avaliação morfológica e funcional das estruturas.

Foram avaliadas as estruturas anatômicas da cavidade nasal (narinas, cornetos, etimóide e recesso faríngeo), as bolsas guturais, o palato mole, a epiglote, a faringe, a laringe, as cartilagens aritenóides, as cordas vocais e a traquéia dos eqüinos levando-se em consideração sua topografia, aspecto e função. Além disso, buscou-se a observação de presença de muco e sangramento. Quando havia sangramento o mesmo era analisado a fim de se graduar a HPIE. Foi utilizada como referência a graduação descrita por Pascoe (1981), conforme segue: Grau I - traços 
de sangue no muco traqueal (Figura 1); Grau II - filetes de sangue com menos de 5 $\mathrm{mm}$ de largura (Figura 2); Grau III - filetes de sangue maiores de $5 \mathrm{~mm}$ e menores de $15 \mathrm{~mm}$ de largura (Figura 3); Grau IV - filetes de sangue mais largos que $15 \mathrm{~mm}$ (Figura 4) e Grau V - filetes de sangue maiores de $15 \mathrm{~mm}$ de largura com epistaxe, e considerou-se Grau 0 como ausência de sangue.

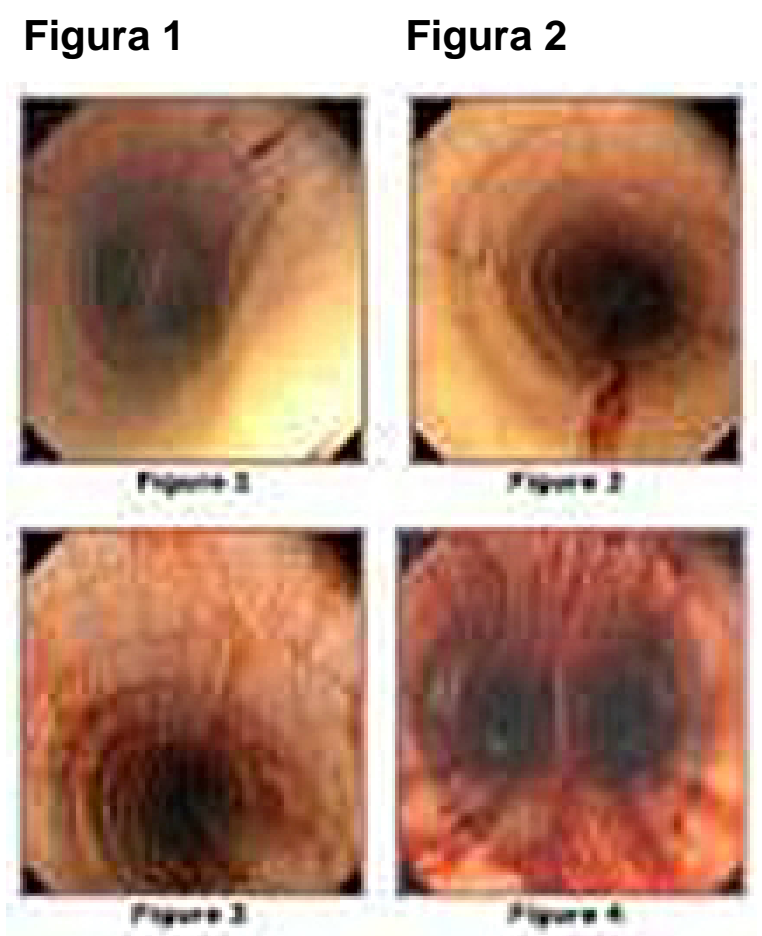

\section{Figura $3 \quad$ Figura 4}

Figura 1 - HPIE GI

Figura 2 - HPIE GII

Figura 3 - HPIE GIII

Figura 4 - HPIE GIV

Os exames endoscópicos foram realizados após 1 hora da participação dos animais em suas respectivas provas. 


\subsection{ANÁLISE DO LTB}

Seguem abaixo a descrição da colheita, as características macroscópicas e a citologia do LTB.

\subsubsection{Colheita do LTB}

As colheitas foram realizadas conforme metodologia descrita por Beech (1991).

As amostras foram obtidas por aspiração pelo canal de trabalho do colonoscópio através de um longo cateter de polietileno acoplado a uma seringa de $20 \mathrm{ml}$. Em cada colheita foram introduzidos $20 \mathrm{ml}$ de solução salina estéril pela seringa, através do cateter de polietileno, a fim de recuperar uma amostra padrão de LTB dos animais.

Após a recuperação das amostras as mesmas eram analisadas macroscopicamente e logo em seguida utilizadas para confecção de lâminas para análise citológica.

O procedimento foi realizado após 1 hora da participação dos animais em provas. 


\subsubsection{Características macroscópicas do lavado traqueobrônquico}

As amostras do LTB foram caracterizadas macroscopicamente de acordo com as variações de coloração, turbidez e quantidade e tamanho de partículas mucóide (Quadro 1).

\begin{tabular}{|c|c|c|c|}
\hline \multicolumn{4}{|c|}{ CARACTERÍSTICAS MACROSCÓPICAS DO LTB } \\
\hline COLORAÇÃO & TURBIDEZ & $\begin{array}{c}\text { QUANTIDADE DE } \\
\text { PARTÍCULAS }\end{array}$ & $\begin{array}{c}\text { TAMANHO DAS } \\
\text { PARTÍCULAS }\end{array}$ \\
\hline Ausente & Transparente & Poucas & Pequenas \\
\hline Amarela & Turvo & Moderada & Grandes \\
\hline Avermelhada & $\ldots$ & Muitas & $\ldots$ \\
\hline Vermelha & $\ldots$ & $\ldots$ & $\ldots$ \\
\hline
\end{tabular}

Quadro 1 - Classificação das amostras do lavado traqueobrônquico colhido dos animais 


\subsubsection{Citologia do lavado traqueobrônquico}

Amostras de $100 \mu \mathrm{L}$ de suspensão celular do lavado traqueobrônquico foram submetidas à citocentrifugação em centrífuga da marca Fanem, modelo 248, a uma velocidade de 2800 rpm durante 6 minutos. Foram confeccionadas 3 lâminas a partir destas amostras citocentrifugadas e 3 lâminas com amostras in natura por método de esfregaço. As mesmas foram coradas posteriormente pelo método de ROSENFELD (FERNANDES et al., 2000). A leitura das lâminas foi realizada em microscopia óptica de imersão em microscópio da marca Olympus, com aumento de 800X, sendo analisadas segundo a qualidade e os tipos celulares predominantes, realizando-se a contagem diferencial. Os resultados obtidos foram expressos em porcentagem dos diferentes tipos celulares (SANCHES, 1998). 


\section{RESULTADOS}

A seguir serão descritos os resultados em relação ao exame físico, exame endoscópico e análise do lavado traqueobrônquico.

\subsection{EXAME FÍSICO}

A seguir serão descritos os resultados dos exames físico realizados nos animais antes e após o exercício.

\subsubsection{Parâmetros obtidos antes do exercício}

O exame físico dos cavalos do grupo A e do grupo B não acusou sinais clínicos que indicassem qualquer enfermidade. As freqüências, cardíaca e respiratória, observadas (média \pm desvio padrão) no grupo A foram de 30,00 \pm 2,11 bpm e 16,15 \pm 4,00 mpm, respectivamente, e do grupo B foram de 29,00 $\pm 2,00 \mathrm{bpm}$ e 17,00 \pm 4,5 mpm, respectivamente, permanecendo dentro dos limites normais descritos para a espécie (SPEIRS, 1997). A temperatura corpórea observada (média \pm desvio padrão) no grupo $A$ foi de $38,00 \pm 0,14^{\circ} \mathrm{C}$ e no grupo $B$ foi de $37,5 \pm 0,2^{\circ} \mathrm{C}$, também dentro dos limites normais descritos para a espécie (SPEIRS, 1997). Estes resultados são apresentados nas tabelas 3 e 4.

O resultado do exame semiológico do sistema respiratório realizado nos animais também se apresentou dentro dos padrões normais para a espécie (SPEIRS, 1977). Apenas um animal do grupo A (17) e um do grupo B (38) apresentaram secreção bilateral de aspecto mucoso, porém não apresentavam outros sinais clínicos que demonstrassem uma possível enfermidade. Estes resultados são apresentados nas tabelas 5 e 6.

A auscultação da traquéia e do tórax dos animais dos grupos $A$ e $B$ revelou a presença de ruídos respiratórios normais. 


\subsubsection{Parâmetros obtidos após o exercício}

Em relação à freqüência cardíaca, a freqüência respiratória e a temperatura corpórea dos animais aferidas após o esforço, não houve alterações que indicassem algum tipo de enfermidade nos animais, apenas mudanças de valores condizentes com o esforço realizado. Estes resultados são apresentados nas tabelas 3 e 4.

No exame semiológico do sistema respiratório dos animais pudemos observar em quase todos os animais do grupo A e do grupo $B$, com exceção dos animais 26 (grupo A) e 30 (grupo B) alteração na coloração da mucosa nasal, mudando de normocorada para hiperêmica, alteração esta condizente com a realização de exercício físico (JONES, 1989). Em relação ao aspecto da secreção, a da maioria dos animais apresentou-se serosa, somente os animais, 8, 14, 15 e 16 do grupo A e o animal 27 do grupo B apresentaram secreção de aspecto mucoso. Os animais 33 e 37 (grupo B) apresentaram sangramento bilateral, indicando assim a possibilidade de hemorragia pulmonar induzida por esforço, mais tarde diagnosticada através do exame endoscópico. Estes resultados são observados nas tabelas 5 e 6 .

Não foi identificada nenhuma alteração referente à auscultação do tórax e da traquéia dos animais após o esforço. 
Tabela 3 - Parâmetros clínicos dos animais do GRUPO A aferidos em repouso e após o esforço

\begin{tabular}{|c|c|c|c|c|c|c|}
\hline \multicolumn{7}{|c|}{ PARÂMETROS CLÍNICOS - GRUPO A } \\
\hline \multicolumn{4}{|c|}{ REPOUSO } & \multicolumn{3}{|c|}{ PÓS-EXERCÍCIO } \\
\hline ANIMAL & FC (bpm) & FR (mpm) & $\mathrm{T}\left({ }^{\circ} \mathrm{C}\right)$ & FC (bpm) & FR (mpm) & $\mathrm{T}\left({ }^{\circ} \mathrm{C}\right)$ \\
\hline 1 & 30 & 12 & 37,7 & 84 & 64 & 38,8 \\
\hline 2 & 32 & 12 & 37,7 & 68 & 44 & 38,9 \\
\hline 3 & 32 & 14 & 37,5 & 80 & 64 & 38,8 \\
\hline 4 & 28 & 12 & 37,6 & 78 & 64 & 38,9 \\
\hline 5 & 26 & 20 & 37,6 & 84 & 52 & 38,7 \\
\hline 6 & 32 & 20 & 37,8 & 96 & 68 & 38 \\
\hline 7 & 30 & 16 & 37,5 & 84 & 64 & 38,9 \\
\hline 8 & 32 & 12 & 37,3 & 80 & 64 & 38,5 \\
\hline 9 & 30 & 16 & 37,5 & 78 & 64 & 38,3 \\
\hline 10 & 26 & 16 & 37,7 & 88 & 68 & 39 \\
\hline 11 & 28 & 20 & 37,8 & 83 & 64 & 38,8 \\
\hline 12 & 28 & 20 & 37,7 & 80 & 64 & 37,9 \\
\hline 13 & 28 & 16 & 37,7 & 93 & 68 & 38 \\
\hline 14 & 30 & 12 & 37,3 & 84 & 64 & 38,3 \\
\hline 15 & 32 & 12 & 37,7 & 84 & 72 & 38,9 \\
\hline 16 & 32 & 20 & 37,5 & 80 & 52 & 38,4 \\
\hline 17 & 30 & 16 & 37,5 & 85 & 72 & 38,7 \\
\hline 18 & 30 & 16 & 37,7 & 79 & 68 & 38,9 \\
\hline 19 & 26 & 12 & 37,8 & 94 & 68 & 39 \\
\hline 20 & 28 & 20 & 37,5 & 95 & 72 & 37,9 \\
\hline 21 & 30 & 20 & 37,6 & 78 & 64 & 38,1 \\
\hline 22 & 32 & 26 & 37,3 & 87 & 64 & 39 \\
\hline 23 & 32 & 16 & 37,5 & 96 & 72 & 39,1 \\
\hline 24 & 32 & 12 & 37,6 & 80 & 64 & 38,9 \\
\hline 25 & 28 & 12 & 37,7 & 88 & 64 & 38,7 \\
\hline 26 & 32 & 20 & 37,7 & 94 & 72 & 38,8 \\
\hline$\ldots$ & $30 \pm 2,11^{*}$ & $16,15 \pm 4^{*}$ & $38 \pm 0,14^{*}$ & $84,61 \pm 7^{*}$ & $64,61 \pm 6,6^{*}$ & $38,62 \pm 0,40^{*}$ \\
\hline
\end{tabular}


Tabela 4 - Parâmetros clínicos dos animais do GRUPO B aferidos em repouso e após o esforço

\begin{tabular}{|c|c|c|c|c|c|c|}
\hline \multicolumn{7}{|c|}{ PARÂMETROS CLÍNICOS - GRUPO B } \\
\hline \multicolumn{4}{|c|}{ REPOUSO } & \multicolumn{3}{|c|}{ PÓS-EXERCÍCIO } \\
\hline ANIMAL & $\mathrm{FC}(\mathrm{bpm})$ & FR (mpm) & $\mathrm{T}\left({ }^{\circ} \mathrm{C}\right)$ & $\mathrm{FC}(\mathrm{bpm})$ & FR (mpm) & $\mathrm{T}\left({ }^{\circ} \mathrm{C}\right)$ \\
\hline 27 & 28 & 8 & 37,7 & 112 & 64 & 38,9 \\
\hline 28 & 28 & 10 & 37,4 & 96 & 72 & 39,4 \\
\hline 29 & 30 & 12 & 37,5 & 122 & 72 & 39,5 \\
\hline 30 & 30 & 14 & 37,7 & 120 & 70 & 39,3 \\
\hline 31 & 32 & 20 & 37,6 & 136 & 78 & 38,8 \\
\hline 32 & 32 & 26 & 37,7 & 156 & 84 & 38,7 \\
\hline 33 & 32 & 18 & 37,4 & 152 & 82 & 39,3 \\
\hline 34 & 28 & 16 & 37,6 & 144 & 89 & 38,9 \\
\hline 35 & 30 & 22 & 37,6 & 124 & 72 & 39 \\
\hline 36 & 28 & 26 & 37,4 & 136 & 76 & 38,9 \\
\hline 37 & 28 & 20 & 37,3 & 147 & 82 & 37,9 \\
\hline 38 & 28 & 12 & 37,1 & 100 & 64 & 38,8 \\
\hline 39 & 26 & 12 & 37,4 & 124 & 84 & 38,6 \\
\hline 40 & 26 & 20 & 37,5 & 121 & 84 & 39,2 \\
\hline 41 & 26 & 20 & 37,5 & 118 & 78 & 39,3 \\
\hline 42 & 30 & 16 & 37,7 & 120 & 86 & 39,4 \\
\hline 43 & 30 & 16 & 37,8 & 136 & 80 & 40 \\
\hline 44 & 32 & 20 & 37,9 & 136 & 90 & 39,9 \\
\hline 45 & 30 & 18 & 37,3 & 147 & 84 & 38,7 \\
\hline 46 & 32 & 16 & 37,7 & 148 & 87 & 39,4 \\
\hline 48 & 26 & 20 & 37,6 & 116 & 78 & 39 \\
\hline 49 & 28 & 16 & 37,7 & 124 & 78 & 38 \\
\hline 50 & 30 & 16 & 37,8 & 118 & 82 & 38,9 \\
\hline$\ldots$ & $29 \pm 2^{*}$ & $17 \pm 4,5^{*}$ & $37,5 \pm 0,2^{*}$ & $128 \pm 15^{*}$ & $79 \pm 7^{*}$ & $39 \pm 0,5^{*}$ \\
\hline
\end{tabular}

*Média e desvio padrão 
Tabela 5 - Resultado do exame semiológico do trato respiratório dos animais do Grupo A observados antes e após o esforço

\begin{tabular}{|c|c|c|c|c|c|c|c|c|}
\hline & \multicolumn{4}{|c|}{ REPOUSO } & \multicolumn{4}{|c|}{ PÓS-EXERCÍCIO } \\
\hline ANIMAL & $\begin{array}{c}\text { Mucosa } \\
\text { Nasal }\end{array}$ & $\begin{array}{c}\text { Secreção } \\
\text { Nasal }\end{array}$ & $\begin{array}{c}\text { Aspecto da } \\
\text { Secreção }\end{array}$ & Auscultação & $\begin{array}{c}\text { Mucosa } \\
\text { Nasal }\end{array}$ & \begin{tabular}{|c|} 
Secreção \\
Nasal
\end{tabular} & \begin{tabular}{|c|} 
Aspecto da \\
Secreção \\
\end{tabular} & Auscultação \\
\hline 1 & Normocorada & Bilateral & Seroso & Sons Normais & Hiperêmica & Bilateral & Seroso & Sons Normais \\
\hline 2 & Normocorada & Bilateral & Seroso & Sons Normais & Hiperêmica & Ausente & - & Sons Normais \\
\hline 3 & Normocorada & Ausente & - & Sons Normais & Hiperêmica & Bilateral & Seroso & Sons Normais \\
\hline 4 & Normocorada & Bilateral & Seroso & Sons Normais & Hiperêmica & Bilateral & Seroso & Sons Normais \\
\hline 5 & Normocorada & Bilateral & Seroso & Sons Normais & Hiperêmica & Bilateral & Seroso & Sons Normais \\
\hline 6 & Normocorada & Ausente & - & Sons Normais & Hiperêmica & Bilateral & Seroso & Sons Normais \\
\hline 7 & Normocorada & Bilateral & Seroso & Sons Normais & Hiperêmica & Bilateral & Seroso & Sons Normais \\
\hline 8 & Normocorada & Bilateral & Seroso & Sons Normais & Hiperêmica & Bilateral & Mucoso & Sons Normais \\
\hline 9 & Normocorada & Ausente & - & Sons Normais & Hiperêmica & Bilateral & Seroso & Sons Normais \\
\hline 10 & Normocorada & Bilateral & Seroso & Sons Normais & Hiperêmica & Bilateral & Seroso & Sons Normais \\
\hline 11 & Normocorada & Bilateral & Seroso & Sons Normais & Hiperêmica & Bilateral & Seroso & Sons Normais \\
\hline 12 & Normocorada & Bilateral & Seroso & Sons Normais & Hiperêmica & Bilateral & Seroso & $\begin{array}{r}\text { Sons Normais } \\
\text { (Continua) }\end{array}$ \\
\hline
\end{tabular}


(Conclusão)

\begin{tabular}{|c|c|c|c|c|c|c|c|c|}
\hline \multicolumn{5}{|c|}{ REPOUSO } & \multicolumn{4}{|c|}{ PÓS-EXERCÍCIO } \\
\hline ANIMAL & $\begin{array}{c}\text { Mucosa } \\
\text { Nasal }\end{array}$ & $\begin{array}{c}\text { Secreção } \\
\text { Nasal } \\
\end{array}$ & $\begin{array}{l}\text { Aspecto da } \\
\text { Secreção }\end{array}$ & Auscultação & $\begin{array}{c}\text { Mucosa } \\
\text { Nasal }\end{array}$ & \begin{tabular}{|c} 
Secreção \\
Nasal \\
\end{tabular} & $\begin{array}{l}\text { Aspecto da } \\
\text { Secreção }\end{array}$ & Auscultação \\
\hline 13 & ormocorada & Ausente & - & Sons Normais & Hiperêmica & Bilateral & Seroso & Sons Normais \\
\hline 14 & Normocorada & Bilateral & Seroso & Sons Normais & Hiperêmica & Bilateral & Mucoso & Sons Normais \\
\hline 15 & Normocorada & Bilateral & Seroso & Sons Normais & Hiperêmica & Bilateral & Mucoso & Sons Normais \\
\hline 16 & Normocorada & Bilateral & Seroso & Sons Normais & Hiperêmica & Bilateral & Mucoso & Sons Normais \\
\hline 17 & Normocorada & Bilateral & Mucoso & Sons Normais & Hiperêmica & Bilateral & Seroso & Sons Normais \\
\hline 18 & Normocorada & Bilateral & Seroso & Sons Normais & Hiperêmica & Bilateral & Seroso & Sons Normais \\
\hline 19 & Normocorada & Bilateral & Seroso & Sons Normais & Hiperêmica & Bilateral & Seroso & Sons Normais \\
\hline 20 & Normocorada & Bilateral & Seroso & Sons Normais & Hiperêmica & Bilateral & Seroso & Sons Normais \\
\hline 21 & Normocorada & Bilateral & Seroso & Sons Normais & Hiperêmica & Bilateral & Seroso & Sons Normais \\
\hline 22 & Normocorada & Bilateral & Seroso & Sons Normais & Hiperêmica & Bilateral & Seroso & Sons Normais \\
\hline 23 & Normocorada & Bilateral & Seroso & Sons Normais & Hiperêmica & Bilateral & Seroso & Sons Normais \\
\hline 24 & Normocorada & Bilateral & Seroso & Sons Normais & Hiperêmica & Bilateral & Seroso & Sons Normais \\
\hline 25 & Normocorada & Bilateral & Seroso & Sons Normais & Hiperêmica & Bilateral & Seroso & Sons Normais \\
\hline 26 & Normocorada & Bilateral & Seroso & Sons Normais & Normocorada & Ausente & _ & Sons Normais \\
\hline
\end{tabular}


Tabela 6 - Resultado do exame semiológico do trato respiratório dos animais do GRUPO B observados antes e após o esforço

\begin{tabular}{|c|c|c|c|c|c|c|c|c|}
\hline & \multicolumn{4}{|c|}{ REPOUSO } & \multicolumn{4}{|c|}{ PÓS-EXERCÍCIO } \\
\hline ANIMAL & $\begin{array}{c}\text { Mucosa } \\
\text { Nasal }\end{array}$ & $\begin{array}{c}\text { Secreção } \\
\text { Nasal }\end{array}$ & \begin{tabular}{|c|} 
Aspecto da \\
Secreção
\end{tabular} & Auscultação & $\begin{array}{c}\text { Mucosa } \\
\text { Nasal }\end{array}$ & $\begin{array}{c}\text { Secreção } \\
\text { Nasal }\end{array}$ & $\begin{array}{l}\text { Aspecto da } \\
\text { Secreção }\end{array}$ & Auscultação \\
\hline 27 & Normocorada & Bilateral & Seroso & Sons Normais & Hiperêmica & Bilateral & Mucoso & Sons Normais \\
\hline 28 & Normocorada & Bilateral & Seroso & Sons Normais & Hiperêmica & Bilateral & Seroso & Sons Normais \\
\hline 29 & Normocorada & Ausente & - & Sons Normais & Hiperêmica & Bilateral & Seroso & Sons Normais \\
\hline 30 & Normocorada & Ausente & - & Sons Normais & Normocorada & Bilateral & Seroso & Sons Normais \\
\hline 31 & Normocorada & Bilateral & Seroso & Sons Normais & Hiperêmica & Bilateral & Seroso & Sons Normais \\
\hline 32 & Normocorada & Bilateral & Seroso & Sons Normais & Hiperêmica & Bilateral & Seroso & Sons Normais \\
\hline 33 & Normocorada & Bilateral & Seroso & Sons Normais & Hiperêmica & Bilateral & Sanguinolento & Sons Normais \\
\hline 34 & Normocorada & Bilateral & Seroso & Sons Normais & Hiperêmica & Bilateral & Seroso & Sons Normais \\
\hline 35 & Normocorada & Bilateral & Seroso & Sons Normais & Hiperêmica & Bilateral & Seroso & Sons Normais \\
\hline 36 & Normocorada & Bilateral & Seroso & Sons Normais & Hiperêmica & Bilateral & Seroso & Sons Normais \\
\hline 37 & Normocorada & Bilateral & Seroso & Sons Normais & Hiperêmica & Bilateral & Sanguinolento & Sons Normais \\
\hline 38 & Normocorada & Bilateral & Mucoso & Sons Normais & Hiperêmica & Bilateral & Seroso & $\begin{array}{l}\text { Sons Normais } \\
\text { (Continua) }\end{array}$ \\
\hline
\end{tabular}


(Conclusão)

\begin{tabular}{|c|c|c|c|c|c|c|c|c|}
\hline \multicolumn{5}{|c|}{ REPOUSO } & \multicolumn{4}{|c|}{ PÓS-EXERCÍCIO } \\
\hline ANIMAL & $\begin{array}{c}\text { Mucosa } \\
\text { Nasal }\end{array}$ & $\begin{array}{c}\text { Secreção } \\
\text { Nasal }\end{array}$ & $\begin{array}{c}\text { Aspecto da } \\
\text { Secreção }\end{array}$ & Auscultação & $\begin{array}{c}\text { Mucosa } \\
\text { Nasal }\end{array}$ & $\begin{array}{c}\text { Secreção } \\
\text { Nasal }\end{array}$ & $\begin{array}{l}\text { Aspecto da } \\
\text { Secreção }\end{array}$ & Auscultação \\
\hline 39 & Normocorada & Ausente & - & Sons Normais & Hiperêmica & Bilateral & Seroso & Sons Normais \\
\hline 40 & Normocorada & Bilateral & Seroso & Sons Normais & Hiperêmica & Bilateral & Seroso & Sons Normais \\
\hline 41 & Normocorada & Bilateral & Seroso & Sons Normais & Hiperêmica & Bilateral & Seroso & Sons Normais \\
\hline 42 & Normocorada & Bilateral & Seroso & Sons Normais & Hiperêmica & Bilateral & Seroso & Sons Normais \\
\hline 43 & Normocorada & Bilateral & Seroso & Sons Normais & Hiperêmica & Bilateral & Seroso & Sons Normais \\
\hline 44 & Normocorada & Bilateral & Seroso & Sons Normais & Hiperêmica & Bilateral & Seroso & Sons Normais \\
\hline 45 & Normocorada & Bilateral & Seroso & Sons Normais & Hiperêmica & Bilateral & Sanguinolento & Sons Normais \\
\hline 46 & Normocorada & Bilateral & Seroso & Sons Normais & Hiperêmica & Bilateral & Seroso & Sons Normais \\
\hline 47 & Normocorada & Bilateral & Seroso & Sons Normais & Hiperêmica & Bilateral & Seroso & Sons Normais \\
\hline 48 & Normocorada & Bilateral & Seroso & Sons Normais & Hiperêmica & Bilateral & Seroso & Sons Normais \\
\hline 49 & Normocorada & Bilateral & Seroso & Sons Normais & Hiperêmica & Bilateral & Seroso & Sons Normais \\
\hline 50 & Normocorada & Bilateral & Seroso & Sons Normais & Hiperêmica & Bilateral & Seroso & Sons Normais \\
\hline
\end{tabular}




\subsection{EXAME ENDOSCÓPICO}

No exame endoscópico realizado nos animais para a observação das vias aéreas anteriores, alterações morfológicas e funcionais foram encontradas em poucos animais dos grupos A e B.

No exame de todos os animais foi observado hiperemia em toda a extensão das vias aéreas anteriores, sendo que nos animais que apresentaram algum grau de sangramento, esta hiperemia era mais evidente e mais acentuada nos animais que apresentaram sangramento em maior grau. Nestes animais, também pode ser observado que os vasos sangüíneos localizados em toda a extensão das vias aéreas anteriores, apresentavam-se ingurgitados e nos animais que apresentaram maior grau de sangramento esta alteração foi mais evidente.

Outra alteração observada em alguns animais foi a hiperplasia linfóide faringeana, porém em grau leve e nem sempre estava associada com os casos de HPIE ocorridos durante este estudo. Os animais 6 e 44 apresentaram hiperplasia de grau I e os animais 27 e 39 apresentaram hiperplasia de grau II. Apenas um animal, o 2, apresentou hemiplegia laringeana, diagnosticada de grau III, pela assimetria da cartilagem aritenóide direita.

Outra alteração encontrada em apenas um animal (30) foi um quadro de empiema de bolsa gutural, de grau leve localizado na bolsa direita. Este animal não apresentou outra alteração, portanto também não observamos casos em que pudéssemos correlacionar HPIE e empiema de bolsa gutural.

Houve grande variação em relação à quantidade e o tipo de secreção encontrada durante o exame endoscópico dos animais dos grupos A e B. Alguns animais não apresentaram secreção, outros animais apresentaram secreção mucopurulenta em quantidades variadas. Além disso, houve casos de HPIE diagnosticados através da visualização de secreção sanguinolenta e sangue na região da traquéia dos animais em quantidades variadas que indicavam diferentes graus da mesma.

A tabela 7 mostra a relação da altura dos obstáculos saltados pelos animais dos grupos A e B, e o grau de HPIE observado durante o exame endoscópico destes animais. 
Tabela 7 - Relação da altura dos obstáculos das provas realizadas pelos animais dos grupos A e B e o grau de hemorragia pulmonar induzida por esforço apresentada durante este estudo

\begin{tabular}{|c|c|c|c|c|c|}
\hline \multicolumn{3}{|c|}{ GRUPO - A } & \multicolumn{3}{|c|}{ GRUPO - B } \\
\hline ANIMAL & ALTURA (M) & $\operatorname{HPIE}(\mathrm{G})$ & ANIMAL & ALTURA (M) & $\operatorname{HPIE}(\mathrm{G})$ \\
\hline 1 & 1.20 & 1 & 27 & 1.30 & 0 \\
\hline 2 & 1.10 & 1 & 28 & 1.30 & 3 \\
\hline 3 & 1.10 & 0 & 29 & 1.30 & 0 \\
\hline 4 & 1.00 & 0 & 30 & 1.30 & 0 \\
\hline 5 & 1.10 & 0 & 31 & 1.40 & 2 \\
\hline 6 & 1.20 & 1 & 32 & 1.50 & 3 \\
\hline 7 & 1.10 & 1 & 33 & 1.50 & 5 \\
\hline 8 & 1.10 & 0 & 34 & 1.40 & 4 \\
\hline 9 & 1.00 & 1 & 35 & 1.30 & 0 \\
\hline 10 & 1.20 & 0 & 36 & 1.40 & 0 \\
\hline 11 & 1.10 & 0 & 37 & 1.50 & 5 \\
\hline 12 & 1.00 & 1 & 38 & 1.40 & 3 \\
\hline 13 & 1.20 & 3 & 39 & 1.30 & 2 \\
\hline 14 & 1.20 & 2 & 40 & 1.30 & 1 \\
\hline 15 & 1.20 & 1 & 41 & 1.30 & 0 \\
\hline 16 & 1.20 & 2 & 42 & 1.30 & 0 \\
\hline 17 & 1.10 & 1 & 43 & 1.40 & 3 \\
\hline 18 & 1.00 & 0 & 44 & 1.40 & 1 \\
\hline 19 & 1.20 & 0 & 45 & 1.50 & 5 \\
\hline 20 & 1.20 & 0 & 46 & 1.50 & 4 \\
\hline 21 & 1.00 & 0 & 47 & 1.30 & 0 \\
\hline 22 & 1.20 & 2 & 48 & 1.30 & 2 \\
\hline 23 & 1.20 & 0 & 49 & 1.30 & 4 \\
\hline 24 & 1.00 & 0 & 50 & 1.40 & 3 \\
\hline 25 & 1.20 & 3 & $\ldots$ & $\ldots$ & $\ldots$ \\
\hline 26 & 1.20 & 0 & $\ldots$ & $\ldots$ & $\ldots$ \\
\hline
\end{tabular}


Através dos dados demonstrados na tabela 7 pudemos definir a quantidade de animais que apresentaram HPIE durante este estudo.

As tabelas 8 e 9 mostram o resultado final deste estudo em relação à ocorrência de casos de HPIE em cavalos de salto. Os resultados estão expressos em números absolutos e porcentagem.

Tabela 8 - Ocorrência de casos de hemorragia pulmonar induzida por esforço em cavalos de salto do GRUPO A

\begin{tabular}{c|c|c|c|c|c}
\hline \multicolumn{7}{c}{ GRUPO A $\mathbf{1 . 0 0 ~ A ~ 1 . 2 0 ~}$} \\
\hline Altura (M) & $\mathbf{1 . 0 0}$ & $\mathbf{1 . 1 0}$ & $\mathbf{1 . 2 0}$ & $\begin{array}{c}\text { Total } \\
\text { (números absolutos) }\end{array}$ & Total (\%) \\
Animais & 6 & 7 & 14 & $\mathbf{2 6}$ & 100 \\
Sangradores & 2 & 3 & 8 & $\mathbf{1 3}$ & 50,00 \\
GI & 2 & 3 & 3 & $\mathbf{8}$ & 61,54 \\
GII & 0 & 0 & 3 & $\mathbf{3}$ & 23,08 \\
GIII & 0 & 0 & 2 & $\mathbf{2}$ & 15,38 \\
GIV & 0 & 0 & 0 & $\mathbf{0}$ & 0,00 \\
GV & 0 & 0 & 0 & $\mathbf{0}$ & 0,00 \\
\hline
\end{tabular}

Tabela 9 - Ocorrência de casos de hemorragia pulmonar induzida por esforço em cavalos de salto do GRUPO B

\begin{tabular}{c|c|c|c|c|c}
\hline \multicolumn{7}{c}{ GRUPO B - 1.30 A 1.50 } \\
\hline Altura (M) & $\mathbf{1 . 3 0}$ & $\mathbf{1 . 4 0}$ & $\mathbf{1 . 5 0}$ & $\begin{array}{c}\text { Total } \\
\text { (números absolutos) }\end{array}$ & Total (\%) \\
\hline Animais & 12 & 7 & 5 & $\mathbf{2 4}$ & 100 \\
Sangradores & 5 & 6 & 5 & $\mathbf{1 6}$ & 66,67 \\
GI & 1 & 1 & 0 & $\mathbf{2}$ & 12,50 \\
GII & 2 & 1 & 0 & $\mathbf{3}$ & 18,75 \\
GIII & 1 & 3 & 1 & $\mathbf{5}$ & 31,25 \\
GIV & 1 & 1 & 1 & $\mathbf{3}$ & 18,75 \\
GV & 0 & 0 & 3 & $\mathbf{3}$ & 18,75 \\
\hline
\end{tabular}




\subsection{ANÁLISE DO LAVADO TRAQUEOBRÔNQUICO}

Segue abaixo a descrição da colheita do LTB.

\subsubsection{Colheita do lavado traqueobrônquico}

Nas diversas colheitas do LTB não houve diferença significativa entre os dois grupos quanto ao volume de amostra recuperado (Tabela 10). 
Tabela 10 - Volume recuperado de amostras do lavado traqueobrônquico

\begin{tabular}{|c|c|c|c|}
\hline \multicolumn{4}{|c|}{ Volume Recuperado (ml) } \\
\hline \multicolumn{2}{|r|}{ Grupo A } & \multicolumn{2}{|c|}{ Grupo B } \\
\hline Animal & Volume (ml) & Animal & Volume (ml) \\
\hline 1 & 18 & 27 & 12 \\
\hline 2 & 12 & 28 & 20 \\
\hline 3 & 12 & 29 & 18 \\
\hline 4 & 14 & 30 & 9 \\
\hline 5 & 13 & 31 & 22 \\
\hline 6 & 13 & 32 & 26 \\
\hline 7 & 16 & 33 & 28 \\
\hline 8 & 13 & 34 & 26 \\
\hline 9 & 18 & 35 & 16 \\
\hline 10 & 14 & 36 & 16 \\
\hline 11 & 15 & 37 & 26 \\
\hline 12 & 20 & 38 & 28 \\
\hline 13 & 22 & 39 & 19 \\
\hline 14 & 24 & 40 & 20 \\
\hline 15 & 18 & 41 & 16 \\
\hline 16 & 22 & 42 & 18 \\
\hline 17 & 18 & 43 & 26 \\
\hline 18 & 14 & 44 & 16 \\
\hline 19 & 14 & 45 & 24 \\
\hline 20 & 16 & 46 & 26 \\
\hline 21 & 16 & 47 & 13 \\
\hline 22 & 20 & 48 & 18 \\
\hline 23 & 18 & 49 & 24 \\
\hline 24 & 13 & 50 & 20 \\
\hline 25 & 22 & $\ldots$ & $\ldots$ \\
\hline 26 & 12 & $\ldots$ & $\ldots$ \\
\hline$\ldots$ & $16,42 \pm 3,58^{*}$ & $\ldots$ & $20,30 \pm 5,33^{\prime}$ \\
\hline
\end{tabular}




\subsubsection{Características macroscópicas do lavado traqueobrônquico}

As características macroscópicas do LTB dos animais do experimento estão apresentadas nas tabelas 11 e 12.

Tabela 11 - Características macroscópicas das amostras do lavado traqueobrônquico dos animais do GRUPO A

\begin{tabular}{|c|c|c|c|c|}
\hline ANIMAL & COLORAÇÃO & TURBIDEZ & $\begin{array}{c}\text { QUANTIDADE } \\
\text { DE PARTÍCULAS }\end{array}$ & $\begin{array}{c}\text { TAMANHO DAS } \\
\text { PARTÍCULAS }\end{array}$ \\
\hline $1^{*}$ & Avermelhada & Turvo & Ausente & - \\
\hline $2^{*}$ & Avermelhada & Turvo & Ausente & - \\
\hline 3 & Amarela & Turvo & Poucas & Pequenas \\
\hline 4 & Ausente & Transparente & Ausente & - \\
\hline 5 & Ausente & Transparente & Ausente & - \\
\hline $6^{*}$ & Avermelhada & Turvo & Poucas & Pequenas \\
\hline $7^{*}$ & Avermelhada & Turvo & Poucas & Pequenas \\
\hline 8 & Ausente & Transparente & Ausente & - \\
\hline $9 *$ & Avermelhada & Turvo & Poucas & \\
\hline 10 & Amarela & Turvo & Poucas & Pequenas \\
\hline 11 & Ausente & Transparente & Ausente & - \\
\hline $12^{*}$ & Avermelhada & Turvo & Poucas & Pequenas \\
\hline $13^{*}$ & Vermelha & Turvo & Poucas & Pequenas \\
\hline $14^{*}$ & Avermelhada & Turvo & Poucas & Pequenas \\
\hline $15^{*}$ & Avermelhada & Turvo & Poucas & Pequenas \\
\hline $16^{*}$ & Avermelhada & Turvo & Ausente & - \\
\hline $17^{*}$ & Avermelhada & Turvo & Poucas & Pequenas \\
\hline 18 & Ausente & Transparente & Ausente & - \\
\hline 19 & Amarela & Turvo & Ausente & Pequenas \\
\hline 20 & Ausente & Transparente & Ausente & - \\
\hline 1 & Amarela & Turvo & Poucas & Pequenas \\
\hline $22^{*}$ & Avermelhada & Turvo & Ausente & - \\
\hline 23 & Ausente & Transparente & Ausente & - \\
\hline 24 & Ausente & Transparente & Ausente & - \\
\hline $25^{*}$ & Vermelha & Turvo & Moderado & Pequenas \\
\hline 26 & Ausente & Transparente & Ausente & - \\
\hline
\end{tabular}


Tabela 12 - Características macroscópicas das amostras do lavado traqueobrônquico dos animais do GRUPO B

\begin{tabular}{|c|c|c|c|c|}
\hline ANIMAL & COLORAÇÃO & TURBIDEZ & $\begin{array}{c}\text { QUANTIDADE } \\
\text { DE PARTÍCULAS }\end{array}$ & $\begin{array}{c}\text { TAMANHO } \\
\text { DAS PARTÍCULAS } \\
\end{array}$ \\
\hline 27 & Amarela & Turvo & Muitas & Pequenas \\
\hline $28^{*}$ & Vermelha & Turvo & Ausente & - \\
\hline 29 & Ausente & Transparente & Ausente & - \\
\hline 30 & Amarela & Turvo & Poucas & Pequenas \\
\hline $31^{*}$ & Avermelhada & Turvo & Muitas & Pequenas** \\
\hline $32^{*}$ & Vermelha & Turvo & Poucas & Pequenas \\
\hline $33^{*}$ & Vermelha & Turvo & Ausente & 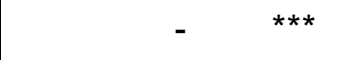 \\
\hline $34^{*}$ & Vermelha & Turvo & Moderado & Pequenas \\
\hline 35 & Ausente & Transparente & Ausente & - \\
\hline 36 & Ausente & Transparente & Ausente & - \\
\hline $37^{*}$ & Vermelha & Turvo & Poucas & Pequenas \\
\hline $38^{*}$ & Vermelha & Turvo & Moderado & Pequenas \\
\hline $39 *$ & Avermelhada & Turvo & Ausente & - \\
\hline $40 *$ & Avermelhada & Turvo & Ausente & - \\
\hline 41 & Amarela & Turvo & Poucas & Pequenas \\
\hline 42 & Amarela & Turvo & Poucas & Pequenas \\
\hline $43^{*}$ & Vermelha & Turvo & Poucas & Pequenas \\
\hline $44^{*}$ & Avermelhada & Turvo & Moderado & Grandes \\
\hline $45^{*}$ & Vermelha & Turvo & Poucas & Pequenas \\
\hline $46^{*}$ & Vermelha & Turvo & Poucas & Pequenas \\
\hline 47 & Ausente & Turvo & Ausente & - \\
\hline $48^{*}$ & Avermelhada & Turvo & Poucas & Pequenas \\
\hline $49 *$ & Vermelha & Turvo & Poucas & Pequenas \\
\hline $50 *$ & Vermelha & Turvo & Poucas & Pequenas \\
\hline
\end{tabular}

**Fig. $n^{\circ} 5$

***Fig. $n^{\circ} 6$ 
As figuras 5 e 6 ilustram algumas amostras descritas nas tabelas.

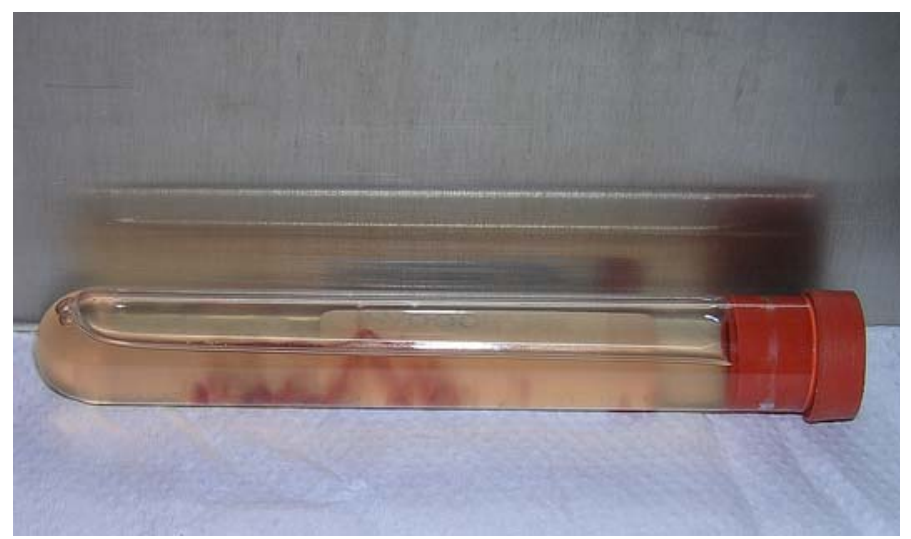

Figura 5 - LTB avermelhado, turvo com muitas partículas pequenas (HPIE GIII)

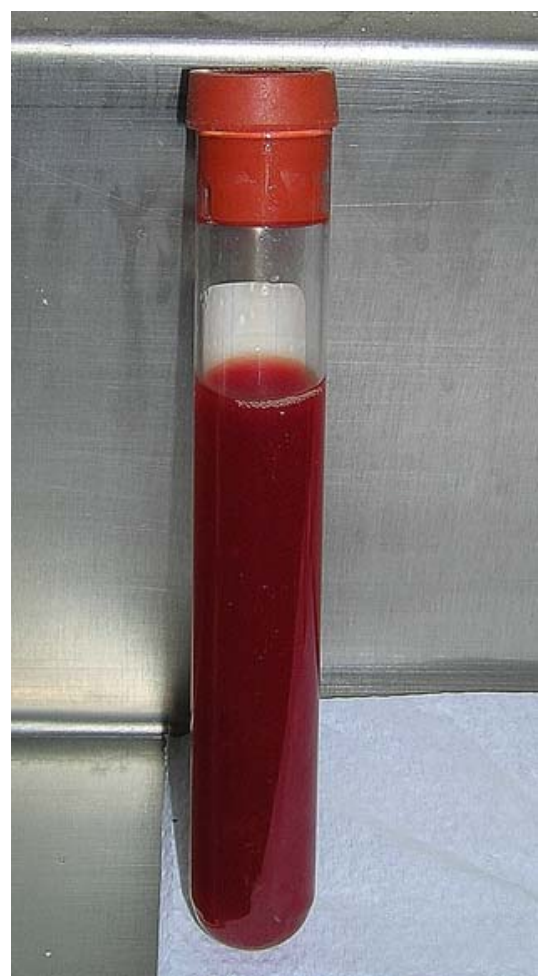

Figura 6 - LTB vermelho, turvo, sem partículas (HPIE GIV) 


\subsubsection{Citologia do LTB}

Na citologia do LTB, os macrófagos foram o tipo celular predominante nos dois grupos e seus valores se alteraram de acordo com o grau de hemorragia pulmonar que o animal apresentava. Conforme o grau de hemorragia pulmonar aumentava, o número de macrófagos diminuía. Em segundo lugar observou-se a presença de hemossiderófagos que aumentavam conforme o grau de hemorragia apresentada pelos animais aumentava também. Em terceiro lugar observou-se a presença de neutrófilos, cujo número manteve-se na mesma média quando relacionados aos diferentes graus de hemorragia e também as células epiteliais cilíndricas ciliadas que seguiam o aumento do grau de hemorragia. Em quarto lugar observou-se a presença dos linfócitos, cujo número manteve-se na mesma média nos diferentes graus de hemorragia pulmonar e por último os eosinófilos que também não apresentaram alteração em suas médias. Não foram encontrados basófilos na citologia realizada neste experimento.

Os resultados estão expressos nas tabelas 13 e 14 . 
Tabela 13 - Média e desvio padrão dos tipos celulares observados nas amostras do lavado traqueobrônquico dos animais do GRUPO A relacionados ao grau de hemorragia pulmonar induzida por esforço

\begin{tabular}{|c|c|c|c|c|c|c|}
\hline \multicolumn{7}{|c|}{ GRUPO A } \\
\hline & G0 & GI & G II & G III & G IV & G V \\
\hline Macrófago & $80,54 \% \pm 3,08 \%$ & $68,54 \% \pm 2 \%$ & $57,11 \% \pm 0,84 \%$ & $54,33 \% \pm 1,41 \%$ & - & - \\
\hline Hemossiderófago & $0,076 \% \pm 0,14 \%$ & $9,83 \% \pm 0,89 \%$ & $14,11 \% \pm 1,01 \%$ & $19,33 \% \pm 0,47 \%$ & - & - \\
\hline Neutrófilo & $10,41 \% \pm 1,35 \%$ & $7,83 \% \pm 1,14 \%$ & $9,78 \% \pm 1,95 \%$ & $9,00 \% \pm 0,47 \%$ & - & - \\
\hline Linfócito & $2,60 \% \pm 1,15 \%$ & $3,00 \% \pm 1,02 \%$ & $4,11 \% \pm 0,38 \%$ & $3,17 \% \pm 0,71 \%$ & - & - \\
\hline Eosinófilo & $0,38 \% \pm 0,23 \%$ & $0,41 \% \pm 0,24 \%$ & $0,55 \% \pm 0,39 \%$ & $0,67 \% \pm 0,00 \%$ & - & - \\
\hline Basófilo & 0 & 0 & 0 & 0 & - & - \\
\hline Cel. Ep. Cilínd. Cil. & $6,00 \% \pm 1,40 \%$ & $10,40 \% \pm 0,90 \%$ & $14,33 \% \pm 1,15 \%$ & $13,5 \% \pm 0,71 \%$ & - & - \\
\hline
\end{tabular}


Tabela 14 - Média e desvio padrão dos tipos celulares observados nas amostras do lavado traqueobrônquico dos animais do GRUPO B relacionados ao grau de hemorragia pulmonar induzida por esforço

\begin{tabular}{|c|c|c|c|c|c|c|}
\hline \multicolumn{7}{|c|}{ GRUPO B } \\
\hline & G0 & G I & G II & G III & G IV & G V \\
\hline Macrófago & $79,21 \% \pm 3,3 \%$ & $68,00 \% \pm 0,47 \%$ & $55,80 \% \pm 0,70 \%$ & $52,30 \% \pm 0,72 \%$ & $48,60 \% \pm 2,52 \%$ & $43,60 \% \pm 0,84 \%$ \\
\hline Hemossiderófago & $0,16 \% \pm 0,17 \%$ & $10,33 \% \pm 0,47 \%$ & $15,67 \% \pm 1,00 \%$ & $19,20 \% \pm 0,50 \%$ & $25,77 \% \pm 4,01 \%$ & $29,00 \% \pm 1,20 \%$ \\
\hline Neutrófilo & $10,42 \% \pm 2,02 \%$ & $7,66 \% \pm 0,50 \%$ & $11,70 \pm 0,90 \%$ & $9,40 \% \pm 1,20 \%$ & $8,44 \% \pm 0,97 \%$ & $8,44 \% \pm 0,51 \%$ \\
\hline Linfócito & $3,41 \% \pm 1,05 \%$ & $3,00 \% \pm 0,00 \%$ & $4,11 \% \pm 0,77 \%$ & $4,13 \% \pm 1,40 \%$ & $3,00 \% \pm 1,00 \%$ & $4,60 \% \pm 1,71 \%$ \\
\hline Eosinófilo & $0,46 \% \pm 0,25 \%$ & $0,33 \% \pm 0,00 \%$ & $0,44 \% \pm 0,20 \%$ & $0,90 \% \pm 0,45 \%$ & $0,60 \% \pm 0,20 \%$ & $0,80 \% \pm 0,51 \%$ \\
\hline Basófilo & 0 & 0 & 0 & 0 & 0 & 0 \\
\hline Cel. Ep. Cilínd. Cil. & $6,34 \% \pm 1,23 \%$ & $10,70 \% \pm 0,48 \%$ & $\mid 12,33 \% \pm 0,33 \%$ & $14,10 \% \pm 0,72 \%$ & $13,70 \% \pm 2,03 \%$ & $13,70 \% \pm 3,40 \%$ \\
\hline
\end{tabular}

As fotomicrografias representativas dos tipos celulares encontrados na citologia das amostras dos LTB pode ser observadas nas figuras, 7 a 11. 


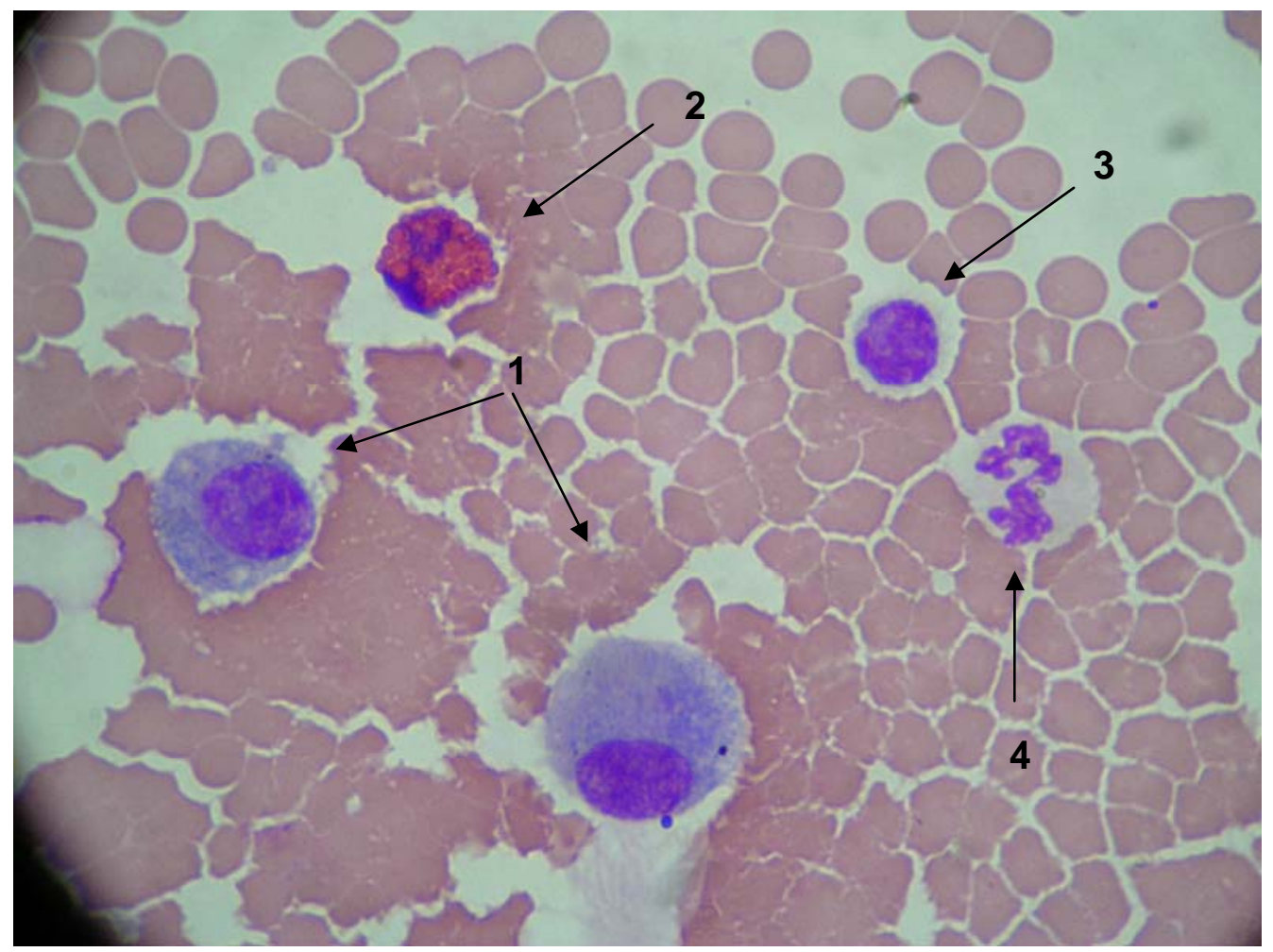

Figura 7 - Fotomicrografia de células do lavado traqueobrônquico. Em destaque: 1. Macrófagos; 2. Eosinófilo; 3. Linfócito; 4. Neutrófilo

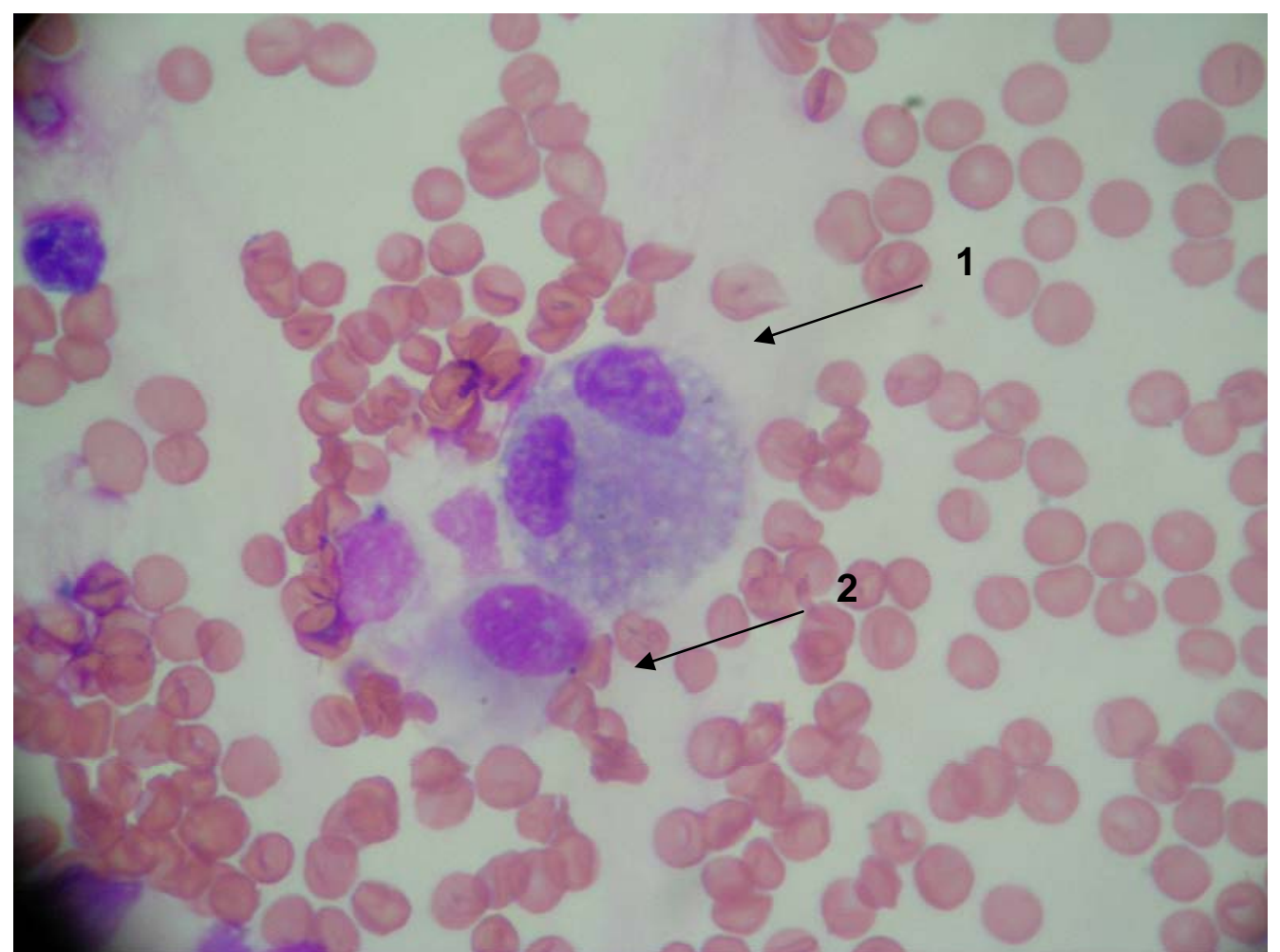

Figura 8 - Fotomicrografia de células do lavado traqueobrônquico. Em destaque: 1. Macrófago binucleado; 2. Macrófago 


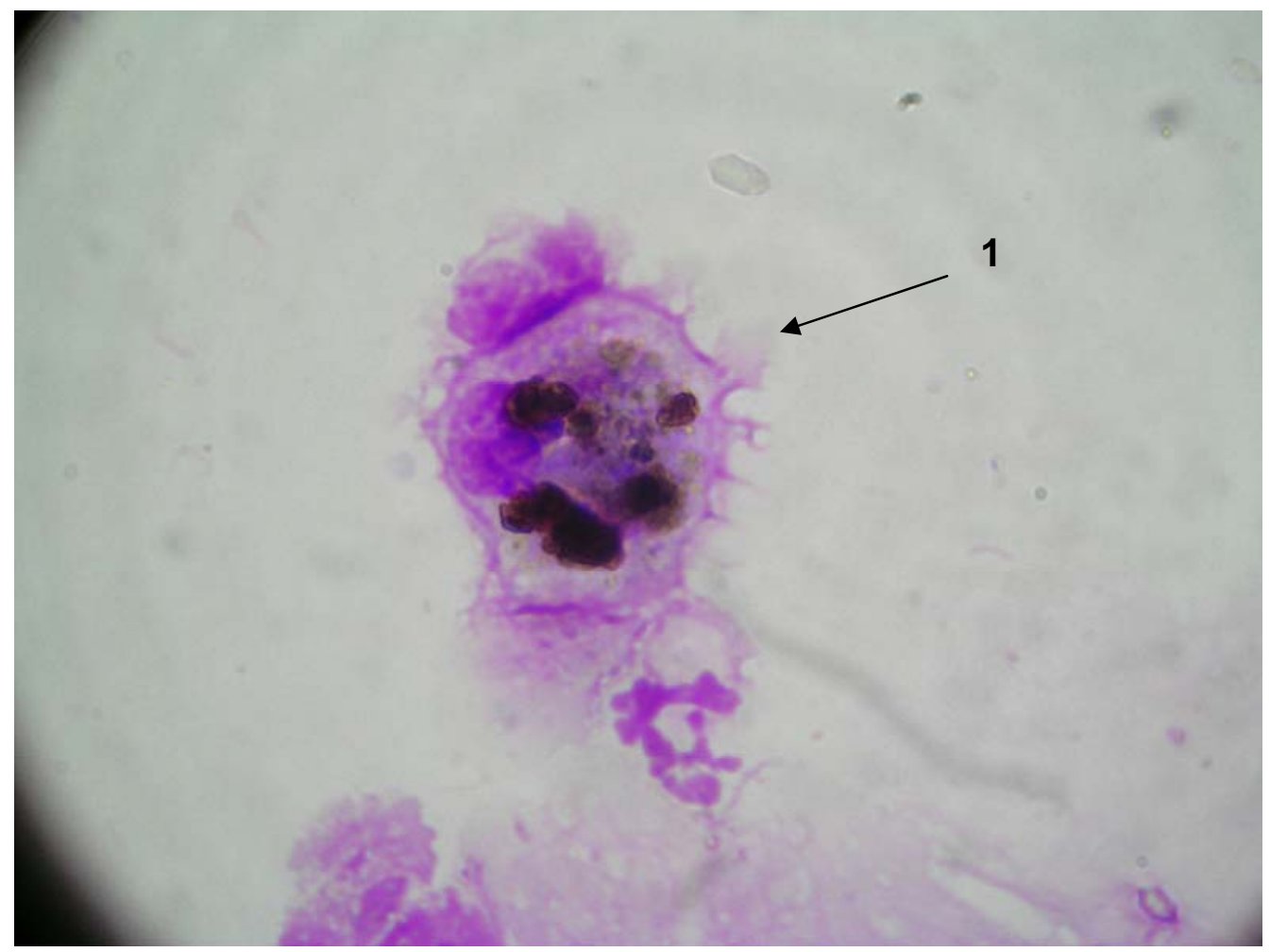

Figura 9 - Fotomicrografia de células do lavado traqueobrônquico. Em destaque: 1. Hemossiderófago

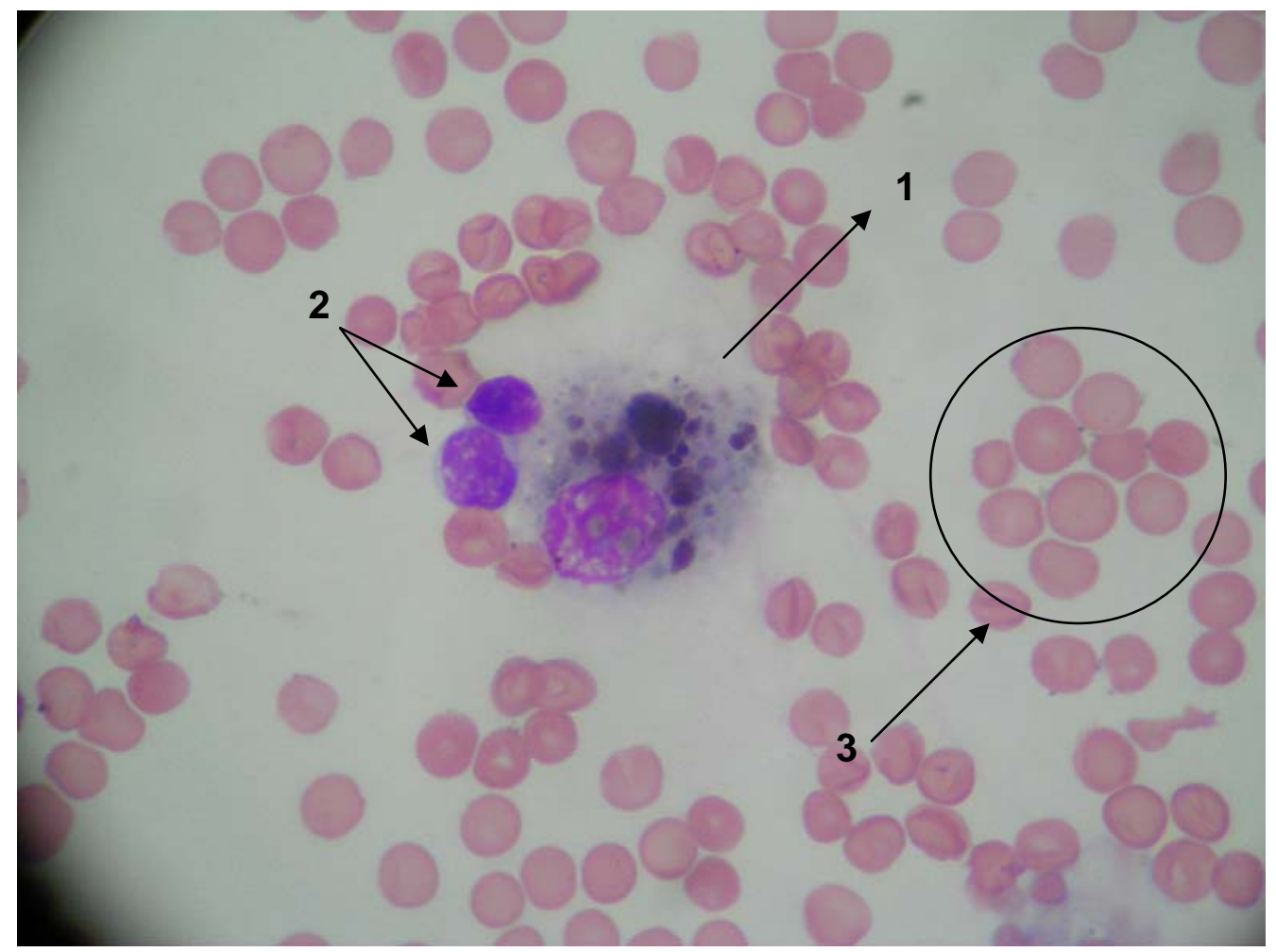

Figura 10 - Fotomicrografia de células do lavado traqueobrônquico. Em destaque: 1. Hemossiderófago; 2. Linfócito; 3. Hemácias 


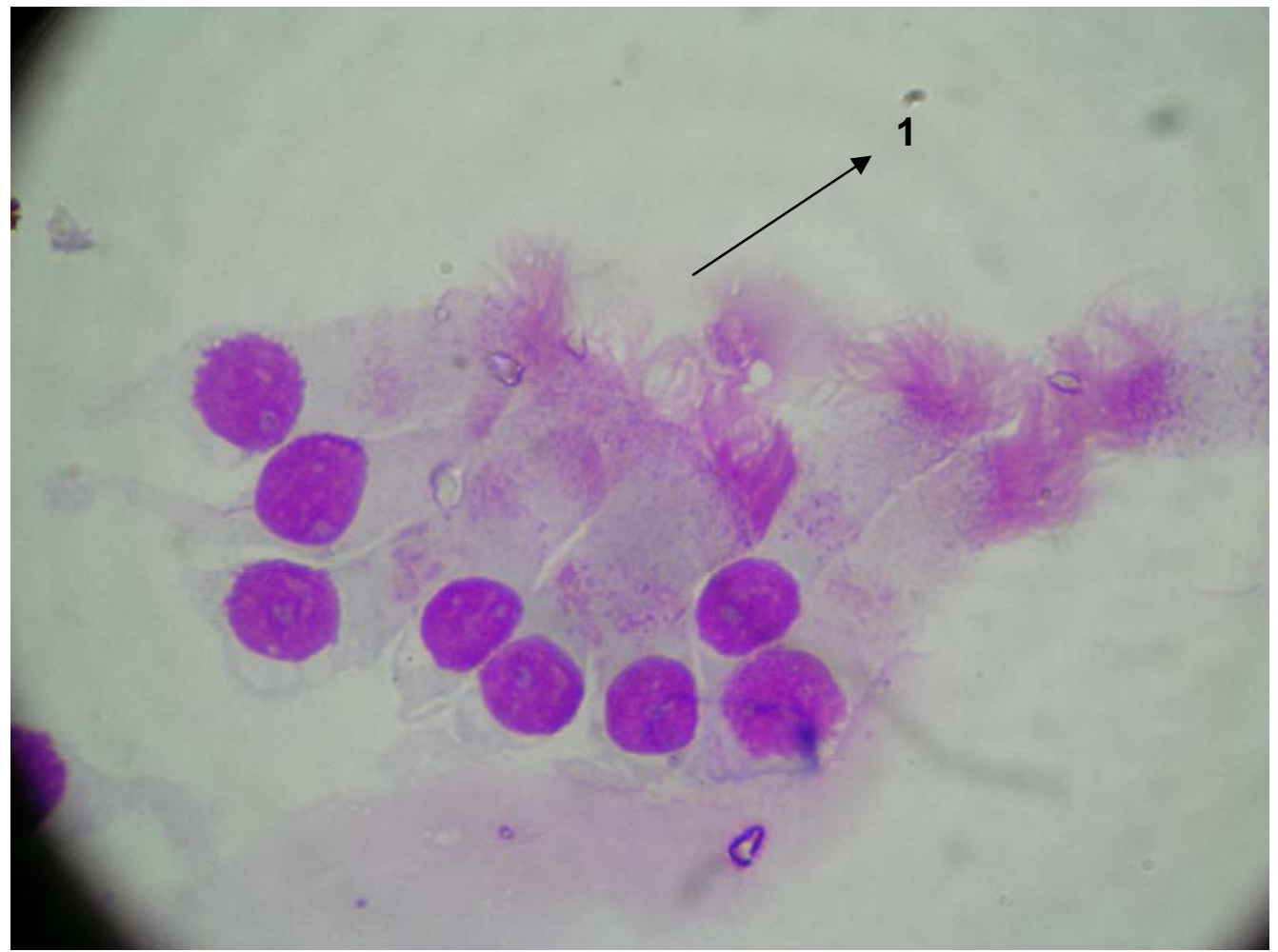

Figura 11 - Fotomicrografia de células do lavado traqueobrônquico. Em destaque: 1 . Células epiteliais cilíndricas ciliadas 


\section{DISCUSSÃo}

Todos os animais foram examinados antes das provas que participaram. Nenhum deles apresentou alteração em relação ao resultado das aferições das freqüências, cardíaca, respiratória e à temperatura corpórea. A avaliação realizada no sistema respiratório também não demonstrou nenhuma alteração clínica nesses animais considerando-se os limites de normalidade descritos para a espécie (SPEIRS, 1997). Após as provas realizadas pelos animais, os mesmos foram submetidos aos mesmos exames descritos acima. O principal resultado observado foi a alteração da freqüência cardíaca, já que este é um dado muito importante em relação à condição física do eqüino atleta. Primeiramente testamos os valores entre os animais dentro de seus grupos, analisando os resultados entre os animais sangradores e não sangradores.

Em relação ao grupo $A$, o valor médio da $F C$ dos animais sangradores foi menor que dos animais não sangradores, portanto neste estudo, não podemos afirmar que os animais do grupo A que apresentaram HPIE tiveram um maior aumento da $\mathrm{FC}$ do que os animais que não apresentaram HPIE. Em relação ao valor médio da FR ocorreu o mesmo fato descrito para FC. Já o valor médio da $T$ foi mais alto nos animais que apresentaram sangramento, porém não foi considerado significativo.

Em relação ao grupo $\mathrm{B}$, o valor médio da $\mathrm{FC}$ dos animais sangradores foi maior que dos animais não sangradores, o que nos possibilitou neste estudo afirmar que os animais do grupo B que apresentaram HPIE tiveram um aumento maior de suas FC. O mesmo ocorreu em relação à FR. Já em relação à $T$ o aumento maior foi observado nos animais que não apresentaram HPIE, porém não foi considerado significativo.

Em uma segunda análise os testes foram realizados entre os grupos $A$ e $B$, os valores confrontados foram, as médias das FC, FR e da $T$ dos animais sangradores do grupo A contra as médias das FC, FR e da $T$ dos animais sangradores do grupo $B$ e também as médias das $F C, F R$ e da $T$ dos animais não sangradores do grupo $A$ contra as médias das FC, FR e da $T$ dos animais não sangradores do grupo $B$. $O$ resultado destes cruzamentos de dados foi o mesmo, a média dos valores das FC, FR e da $T$ dos animais do grupo B foi maior que a do grupo A. Esses dados 
ratificaram a diferença entre os grupos $A$ e $B$, constatada e relatada neste estudo em relação ao nível de esforço realizado pelos animais nas provas. Nos animais do grupo A o aumento da FC após a prova foi de 2,8 vezes, o da FR foi de 4 vezes; no grupo B o aumento da FC após a prova foi de 4,4 vezes, o da FR foi de 4,6 vezes; o aumento da T não foi significativo nos dois grupos. A variação entre estes valores se deu pelo nível de esforço realizado por cada animal de acordo com a diferença entre as alturas dos obstáculos presentes nas provas realizadas por eles, e foram consideradas condizentes com o esforço realizado, baseado nos dados apresentados por Jones (1989), para os valores de freqüência cardíaca nos animais que participam de provas de corrida.

Fizemos tal comparação porque não encontramos um estudo que especificasse as alterações de freqüência cardíaca em cavalos que participam de provas de salto levando em consideração a diferença entre as modalidades, já que o esforço realizado por um cavalo em uma prova de corrida é diferente do esforço realizado por um cavalo em uma prova de salto. Nas corridas o exercício praticado é basicamente aeróbico, o animal alcança seu esforço máximo (velocidade máxima) no final da prova. Já nas provas de salto o animal alterna momentos de exercício aeróbico e anaeróbico, variando sua velocidade durante o percurso de acordo com os obstáculos presentes nas mesmas bem como realizando uma série de movimentos para executar o salto dos mesmos.

As alterações no resultado da freqüência respiratória e da temperatura corpórea também foram consideradas normais em função do esforço realizado pelos animais, levando em consideração dados descritos em um estudo realizado por Mattos et al. (2006), com animais do $3^{\circ}$ Esquadrão de Polícia Montada de Brasília, no Distrito Federal, submetidos a uma série de exercícios incluindo passo, trote e galope durante duas horas, já que não foi encontrado este tipo de estudo realizado especificamente com animais que participam de provas de salto.

Além dos exames descritos acima também foi realizado o exame endoscópico. Este foi essencial para a observação dos casos de hemorragia pulmonar induzida por esforço (HPIE) nos graus I a IV e para realização das colheitas dos lavados traqueobrônquicos (LTB) dos animais deste estudo. O sangramento nasal raramente ocorre, portanto ao avaliarmos as possíveis causas de mau desempenho do animal, o exame endoscópico após o exercício é fundamental. Vale ressaltar que as endoscopias foram realizadas após provas, tendo em vista que nessa condição se 
espera o grau máximo de esforço que o animal é capaz de suportar e, portanto ocorrem nesse momento as maiores alterações possíveis nos sistemas circulatório e respiratório dos animais.

Poucos animais deste estudo apresentaram nos resultados do exame endoscópico alterações morfológicas, representadas por, hiperemia da mucosa e ingurgitamento dos vasos sangüíneos das vias aéreas anteriores, hiperplasia linfóide, empiema de bolsa gutural e hemiplegia laringeana. Não houve nenhum caso em que observamos correlação entre HPIE e Hemiplegia Laringeana, também não tivemos casos em que pudemos correlacionar HPIE e empiema de bolsa gutural.

Houve grande variação observada em relação à quantidade e o tipo de secreção encontrada durante os exames endoscópicos. A principal observação foi em relação à presença de secreções sanguinolentas e sangue nas vias aéreas anteriores dos animais deste estudo, evidenciando casos de HPIE que foram graduados de acordo com a quantidade deste tipo de secreção (PASCOE, 1981).

Pudemos notar que a HPIE apresentada em 50\% dos animais do grupo A e $66,67 \%$ dos animais do grupo B estava relacionado com o esforço exercido pelos animais. Foram observados todos os graus de HPIE (grau I a V), porém os graus mais altos, graus IV e V, somente foram observados em animais do grupo $B$, que participaram de provas com obstáculos mais altos $(1.30 \mathrm{~m}, 1.40 \mathrm{~m}$ e $1.50 \mathrm{~m})$, ratificando assim a relação entre o nível de esforço exercido pelos animais e o grau de HPIE apresentado por eles.

Outro procedimento realizado durante este estudo foi $\mathrm{a}$, análise do lavado traqueobrônquico (LTB) colhido durante o exame endoscópico. Não houve nenhum problema em relação à utilização da técnica proposta durante o estudo. Recuperaram-se amostras de todos os animais sem a necessidade de sedá-los para executar o procedimento como foi proposto no estudo.

O resultado do volume recuperado das amostras não demonstrou diferença significativa entre os grupos. As características macroscópicas observadas foram classificadas de acordo com uma tabela proposta no próprio estudo e pode-se observar diferenças entre os grupos em relação à coloração e a turbidez das amostras. No grupo A a coloração avermelhada (42\%) foi a que mais se observou, seguida da coloração ausente (34\%), amarela (15\%) e vermelha (9\%), no grupo B a 
coloração vermelha (46\%) foi a que mais se observou, seguida da coloração avermelhada (20\%), ausente (17\%) e amarela (17\%).

Foi realizado também o estudo citológico das amostras através de lâminas confeccionadas durante todo o estudo. Os resultados foram obtidos mediante a leitura de seis lâminas por animal conforme método proposto. Os tipos celulares encontrados seguem os padrões descritos por Sweeney e Beech (1991) e Fernandes et al. (2000). Os macrófagos foram o tipo celular mais encontrado nas amostras dos LTB, os hemossiderófagos, macrófagos alveolares que fagocitaram as hemácias em nível pulmonar, foram o segundo tipo celular mais encontrado e sua quantidade era relacionada com o grau de HPIE apresentado pelos animais, quanto maior o grau, maior era o número de hemossiderófagos encontrados nas amostras. Os outros tipos celulares observados mantiveram um valor médio em todos os graus de HPIE e encontravam-se respectivamente na seguinte ordem em relação à quantidade, neutrófilos, células epiteliais cilíndricas ciliadas e eosinófilos, e eram condizentes com os padrões de normalidade descritos por Sanches (1998), Forgaty (1990) e Fernandes et al. (2000).

A utilização do método de coloração por Rosenfeld (1947), para a citologia das amostras do lavado traqueobrônquico demonstrou ser uma técnica prática, rápida e permitiu a caracterização e a diferenciação dos diversos tipos celulares no LTB.

O estudo citológico realizado no presente estudo foi muito importante para relacionar os tipos celulares encontrados nas amostras ao grau de HPIE que os animais apresentaram, principalmente em relação à presença e quantidade de hemossiderófagos. 


\section{CONCLUSÕES}

- Através do presente estudo conclui-se que os eqüinos utilizados na prática de salto podem ser acometidos de hemorragia pulmonar induzida por esforço (HPIE).

- Concluiu-se também que quanto maior o esforço realizado pelos cavalos que participam de provas de salto, ou seja, quanto maior forem os obstáculos presentes nas provas praticadas por estes animais, maior a ocorrência de hemorragia pulmonar induzida por esforço e maior a intensidade desta.

- Não existe relação entre a hemorragia pulmonar induzida por esforço e as alterações de freqüências cardíaca e respiratória e temperatura corpórea que ocorrem em função do esforço físico. 


\section{REFERÊNCIAS}

BACCARIN, R. Y.A. Diagnóstico e tratamento das pneumopatias de esforço. In: SIMPÓSIO INTERNACIONAL DO CAVALO ATLETA $2^{\circ}$, SEMANA DO CAVALO - SIMCAV, 4, 2005 , Belo Horizonte, Anais.: p. 12-28.

BAIN, F. T. Cytology of the respiratory tract. The Veterinary Clinics of North America Equine Pratice, v. 13, n. 3, p. 477-486, 1997.

$\mathrm{BEECH}, \mathrm{J}$. Tracheobronchial aspirates. In: $\mathrm{BECCH}, \mathrm{J}$. Equine respiratory disorders. Philadelphia: Lea e Febiger, 1991. p. 42-61.

BIRGEL, E. H. Patologia clínica veterinária. In: BIRGEL, E. H.; BENESI, F. J. Patologia clínica veterinária. São Paulo: Sociedade Paulista de Medicina Veterinária, 1982. p.1-50.

CARNEIRO, G. F. Afecções do sistema respiratório relacionadas à performance do cavalo atleta. Revista do Conselho Federal de Medicina Veterinária, v. 8 , n. 26, p. 57-70, 2002.

CLARKE, A. F. Review of exercise induced pulmonary haemorrhage and its possible relationship with mechanical stress. Equine Veterinary Journal, v. 17, n. 3, p. 166-172, 1985.

COOK, W. R. Epistaxis in the Racehorses. Equine Veterinary Journal, v. 6, n. 2, p. 45-58, 1974.

DERKSEN, F. J. Applied respiratory physiology. In: BECCH, J. Equine respiratory disorders. Philadelphia: Lea e Febiger, 1991. p.1-25.

DONALDSON, L. L. A Review of the pathophysiology of the exercise-Induced pulmonary hemorrhage in the equine athlete. Veterinary Research

Communications, v. 15, p. 211-226, 1991. 
DOUCET, M. Y.; VIEL, L. Clinical, radiographic, endoscopic, bronchoalveolar lavage and lung biopsy findings in horses with exercise-induced pulmonary hemorrhage. Canadian Veterinary Journal, v. 43, p. 195-202, 2002.

ERICKSON, H. H. A Review of exercise-induced pulmonary hemorrhage and new concepts for prevetion. AAEP Proceedings, v. 46, p. 193-196, 2000.

FERNANDES, W. R.; MORI, E.; SANCHES, A. Avaliação citológica de lavados traqueobrônquicos e broncoalveolar em cavalos clinicamente sadios pelo método de coloração de Rosenfeld. Brazilian Journal of Veterinary and Animal Sciences, São Paulo, v. 52, n. 6, p. 555-668, 2000.

FORGATY, U. Evaluation of a bronchoalveolar lavage technique. Equine Veterinary Journal, v. 22, n. 3, p. 174-176, 1990.

FORGATY, U; BUCKLEY, T. Bronchoalveolar lavage findings in horses with exercise intolerance. Equine Veterinary Journal, Newmarket, v. 23, n. 6, p. 434-437, 1991.

FREEMAN, D. E. Trachea. In: BECCH, J. Equine respiratory disorders. Philadelphia: Lea e Febiger, 1991, p. 389-401.

FREEMAN, K. P.; ROSZEL, J. F.; MCCLURE, J. M.; MANNSMAN, R.; PATTON, P. E.; NAILE, S. A review of cytological specimens from horses with and without clinical sings of respiratory disease. Equine Veterinary Journal, v. 25, n. 6, p. 523-526, 1993.

HOFFMAN, A. M.; VIEL, L. Techniques for sampling the respiratory tract of horses. The Veterinary Clinics of North America Equine Pratice, v. 13, n. 3, p. 463-475, 1997. 
LESTER, G.; CLARK C.; RICE B. Effect of timing and route of administration of furosemide on pulmonary hemorrhage and pulmonary arterial pressure in exercising thoroughbred racehorses. American Journal Veterinary Research, v. 60 , n. 1, p. 22-8, 1999.

MAIR, T. S.; STOKES, C. R.; BOURNE, F. J. Cellular content of secretions obtained by lavage from different levels of the equine respiratory tract. Equine Veterinary Journal, v. 19, n. 5, p. 458-462, 1987.

MANOHAR, M.; HUTCHENS, E; CONEY, E. Pulmonary Haemodynamics in the exercising horse and their relationship to exercise- induced pulmonary haemorrhage. British Veterinary Journal, v. 149, p. 419-429, 1993.

MANOHAR, M. Pulmonary vascular pressures of Thoroughbreds increase rapidly and to a higher level with rapid onset of high-intensity exercise than slow onset. Equine Veterinary Journal, v. 26, n. 6, p 496-99, 1994.

MARLIN, D. Exercise-induced pulmonary haemorrhage. In: CONGRESSO INTERNACIONAL DE MEDICINA VETERINÁRIA ESPORTIVA EQUINA, 1., 2001, Botucatu. Anais.: Botucatu: Depto. de Cirurgia e Anestesiologia Veterinária "Centro de Medicina Eqüina" da FMVZ-UNESP Botucatu, 2001. p. 11.

MCKANE, S. A.; CANFIELD, P. J.; ROSE R. J. Equine bronchoalveolar lavage cytology: survey of Thoroughbred racehorses in training. Australian Veterinary Journal, v. 70, n. 11, p. 401-404, 1993.

MEYER, T. S.; FEDDE, M. R.; GAUGHAN, E. M.; LANGSETMO, I.; ERICKSON, H. H. Quantification of exercise-induced pulmonary haemorrhage with bronchoalveolar lavage. Equine Veterinary Journal, Newmarket, v. 30, n. 4, p. 284-288, 1998. 
MORI, E. Avaliação da função dos macrófagos alveolares após infecção experimental em cavalos (Equus cabalus - Linnaeus, 1758) por herpesvírus eqüino tipo 1 (HVE-1). 2000. 98 p. Dissertação (Mestrado) Faculdade de Medicina Veterinária e Zootecnia.,Universidade de São Paulo, São Paulo, 2000.

O' CALLAGHAN, M. W.; PASCOE, J. R.; TYLER, W. S.; MASON, D. K. Exercise-induced pulmonary haemorrhage in the horse: results of a detailed clinical, post mortem and imaging study. VII. Conclusions and implications. Equine Veterinary Journal, Newmarket, v. 19, n. 5, p. 428-434, 1987.

PASCOE, J. R. Exercise-Induced Pulmonary Hemorrhage. In: BECCH, J. Equine respiratory disorders. Philadelphia: Lea e Febiger, 1991. p. 237-252.

PASCOE, J. R. Why does exercise induced pulmonary haemorrhage occur. Equine Veterinary Journal, Newmarket, v. 17, n. 3, p. 159-165, 1985.

PASCOE, J. R.; ERICKSON, H. H.; O’DEA, J. C. Exercise-Induced Pulmonary Hemorrhage (EIPH). Journal of Equine Veterinary Science, New York, v. 15, n. 11, p. 464-466, 1995.

PASCOE, J. R.; MCCABE A. E.; FRANTI C. E.; ARTHUR R. M. Efficacy of furosemide in the treatment of exercise-induced pulmonary hemorrhage in Thoroughbred racehorses. American Journal Veterinary Research, v. 46, n. 9, p. 200-203, 1985.

ROBERTSON, J. T. Pharynx and larynx. In: BEECH, J. Equine respiratory disorders. Philadelphia: Lea e Febiger, 1991. p. 331-387.

ROSENFELD, G. Corante pancrômico para hematologia e citologia clínica. Nova combinação dos componentes do May-Grunwald e do Giemsa num só corante de emprego rápido. Memórias do Instituto Butantã, v. 20, p. 329-335, 1947. 
SANCHES, A. Avaliação citológica do lavado traqueobrônquico de eqüinos clinicamente sadios e daqueles portadores de afecções do sistema respiratório. 1998. 148 p. Dissertação (Mestrado) - Faculdade de Medicina Veterinária e Zootecnia, Universidade de São Paulo, São Paulo, 1998.

SPEIRS, V. C. Clinical examination of horses. Philadelphia: W. B. Saunders Company, 1997. p. 358.

SWEENEY, C. R.; BEECH, J. Bronchoalveolar lavage, In: BEECH, J. Equine respiratory disorders. Philadelphia: Lea e Febiger, 1991. p.55-61.

SWEENEY, C. R.; SOMA L. R.; BUCAN C. A.; RAY, S. G. Exercise-induced pulmonary hemorrhage in exercising Thoroughbreds: preliminary results with pre-exercise medication. Cornell Veterinary, v. 74, p. 263-268, 1984.

TIZARD, I. Basic Immunology - 3: the importance of macrophages. Veterinary Medicine, v. 81, n. 3, p. 250-2577, 1986.

VIEL, L.; DOUCET, M. Y. Clinical, radiographic, endoscopic, bronchoalveolar lavage and lung biopsy findings in horses with exercise-induced pulmonary hemorrhage. Canadian Journal of Veterinary Research, v. 43, p. 195-202, 2002.

WEISS, D. J.; SMITH, C. M. Hemorrhageological alterations associated with competitive racing activity in horses: Implications for exercise-induced pulmonary haemorrhage (EIPH). Equine Veterinary Journal, Newmarket, v. 30, n. 1, p. 7-12, 1998.

WHITWELL, K. E.; GREET, T. R. C. Collection and evaluation of tracheobronchial washes in the horse. Equine Veterinary Journal, v. 16, n. 6, p. 499-508, 1984. 